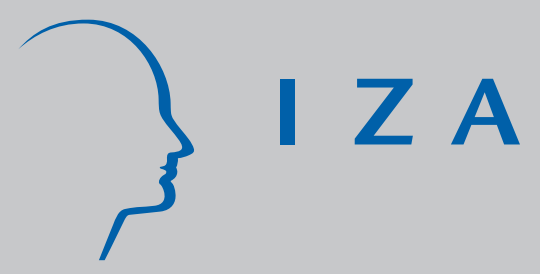

IZA DP No. 1261

Why Do Part-Time Workers Earn Less?

The Role of Worker and J ob Skills

Barry T. Hirsch

August 2004 


\title{
Why Do Part-Time Workers Earn Less? The Role of Worker and Job Skills
}

\author{
Barry T. Hirsch \\ Trinity University \\ and IZA Bonn
}

\section{Discussion Paper No. 1261 \\ August 2004}

\author{
IZA \\ P.O. Box 7240 \\ 53072 Bonn \\ Germany \\ Phone: +49-228-3894-0 \\ Fax: +49-228-3894-180 \\ Email: iza@iza.org
}

\begin{abstract}
Any opinions expressed here are those of the author(s) and not those of the institute. Research disseminated by IZA may include views on policy, but the institute itself takes no institutional policy positions.

The Institute for the Study of Labor (IZA) in Bonn is a local and virtual international research center and a place of communication between science, politics and business. IZA is an independent nonprofit company supported by Deutsche Post World Net. The center is associated with the University of Bonn and offers a stimulating research environment through its research networks, research support, and visitors and doctoral programs. IZA engages in (i) original and internationally competitive research in all fields of labor economics, (ii) development of policy concepts, and (iii) dissemination of research results and concepts to the interested public.
\end{abstract}

IZA Discussion Papers often represent preliminary work and are circulated to encourage discussion. Citation of such a paper should account for its provisional character. A revised version may be available directly from the author. 
IZA Discussion Paper No. 1261

August 2004

\section{ABSTRACT}

\section{Why Do Part-Time Workers Earn Less? The Role of Worker and Job Skills*}

The wages of part-time workers are considerably lower than are those of full-time workers. Measurable worker and job characteristics, including occupational skill requirements, account for much of the part-time penalty. Longitudinal analysis indicates that much of the remaining gap reflects worker heterogeneity, evidenced by small wage gains and losses among workers switching between part-time and full-time jobs. The lower skills of part-time than fulltime workers result primarily from limited work experience and accumulation of human capital. Little evidence can be found of a large wage gap between part-time and full-time women. A part-time wage penalty is found for men, but men account for a small proportion of total part-time employment.

JEL Classification: J31, J24, J22

Keywords: part-time, wages, job characteristics, worker heterogeneity

Barry T. Hirsch

Department of Economics

Trinity University

San Antonio, TX 78212-7200

USA

Email: bhirsch@trinity.edu

\footnotetext{
* The author appreciates comments received from Susan Averett, Hank Farber, Justin Graham, Darren Grant, Julie Hotchkiss, Dan McMillen, two anonymous referees, and participants at university seminars and scholarly meetings.
} 


\section{Introduction}

Part-time jobs pay substantially lower wages and benefits than do full-time jobs. Part-time jobs received considerable public scrutiny following a 1997 strike at United Parcel Service, where the wages and use of part-time workers were key issues of conflict. Discussions about "good" and "bad" jobs and the gender wage gap make frequent reference to part-time work. ${ }^{1}$ Although some of the wage gap can be accounted for by standard measures of worker and job attributes, most studies conclude that a sizable parttime penalty remains. For example, Blank (1990) obtains part-time penalty estimates of $19 \%$ and $26 \%$ for women and men, respectively, after controlling for worker, job, and labor market characteristics. ${ }^{2}$

Understanding the sources of the part-time penalty is important for at least two reasons. First, parttime employment is widespread. In 2003, $17.7 \%$ of workers were part-time, $25.6 \%$ of all women and $10.8 \%$ of men, with women constituting 67.4\% of the part-time workforce (Bureau of Labor Statistics 2004, Table 8). Second, although standard theory provides reasons why there can exist a part-time wage penalty, a large gap among workers with similar skills would be inconsistent with competitive labor markets.

In this paper, we examine the role of worker-specific skills, occupational skill requirements, and job working conditions on the part-time/full-time wage differential. The analysis extends previous research in two directions. First, we construct large panels of workers from the Current Population Survey (CPS), permitting us to observe wage differences among workers who switch between part- and full-time jobs and those remaining at part- and full-time jobs in consecutive years. The longitudinal analysis provides a method for controlling for unmeasured worker-specific skills or preferences fixed across jobs. Second, we incorporate information from the Labor Department's new Occupational Information Network database (known as $O^{*} N E T$ ) on job skill requirements and working conditions.

In section II, we provide explanations for why wage differences exist between part- and full-time jobs and review previous literature. The estimation approach is outlined in section III. Section IV describes the data, while section V provides descriptive evidence. Principal results from the empirical analysis are analyzed in section VI. Section VII provides additional evidence, followed by conclusions in Section VIII.

\section{Why Do Part-Time Jobs Pay Less?}

\section{A. Standard Theory}

Part-time wage differentials can result from differences in labor supply among heterogeneous

\footnotetext{
${ }^{1}$ Public discussion of part-time work is sometimes entangled with discussion of firms' use of contingent or temporary workers (see, for example, AFL-CIO, 1998). For descriptive analysis of contingent workers and alternative work arrangements, see Christensen Sethi (2002).

2 These estimates are obtained for 1987 using OLS with a part-time dummy variable. Blank (1990) subsequently obtains a wide range of estimates using instrumental variable and selectivity estimation approaches.
} 
workers, employer preferences, fixed employment costs, and job search differences. The labor supply explanation starts from the premise that some persons prefer to work part-time rather than full-time (and vice-versa). Young people working while in school, adults heavily engaged in home production, or older workers who have moved out of career jobs may have a strong preference for part-time employment and be willing to accept low wages. Given heterogenous preferences, the supply of full-time relative to part-time workers is upward sloping with respect to relative compensation in full- and part-time jobs. ${ }^{3}$

Differences in preferred hours worked is not a sufficient condition to produce a part-time penalty. If workers preferring part- and full-time hours had identical skills and there were no fixed costs to employers, wage rates could be equalized as firms adjust their worker mix to reflect the preferences of employees. A wage differential arises if part- and full-time workers are heterogeneous (not fully fungible) and employers are not indifferent as to how they schedule hours among workers. For example, "college towns" have many students willing to work part-time, but who care very much which hours they work and possess a different set of skills than demanded by employers for full-time jobs. These factors combine to create wage differences that are not eliminated by employee movement across jobs or employer shifts in the hours mix within jobs. In short, heterogeneous skills, worker differences in preferred hours, and employer preferences create an equilibrium wage gap between part- and full-time workers. ${ }^{4}$

Fixed employer costs provide an additional factor that may produce a wage differential. Costs associated with recruiting, hiring, and training, plus nonwage benefits not proportional to hours (e.g., health insurance), increase the average hourly cost of part-time relative to full-time workers. There must exist a wage differential that equalizes the marginal products per dollar of employing part-time and full-time workers. While marginal employment costs are equalized, the marginal cost of hours will be lower for parttime workers. ${ }^{5}$ It follows that fixed employment costs make it likely that part-time employees receive fewer nonwage benefits than full-time workers. Were it not for the lower benefits, the wage gap would be larger.

Although emphasis is given to factors that lower part-time wages, some forces work in an opposing direction. If firms have peak labor (customer) demand over brief intervals (e.g., restaurants with mealtime peaks), but most workers prefer continuous hours rather than brief or split shifts, part-time wages could

\footnotetext{
${ }^{3}$ Euwals and Hogerbrugge (2004) examine supply and demand determinants of part-time employment across time within the Netherlands and among other OECD countries. They conclude that female labor force participation is the principal determinant of differences in part-time employment across time and countries.

${ }^{4}$ A part-time wage differential also can arise if workers are willing to take low paid part-time jobs as a way of queuing for full-time jobs with efficiency wages or other forms of rents. Relatively few persons are classified as "involuntary" part-time workers (i.e., part-time workers stating that they want to work a full-time workweek).

${ }^{5}$ Where workers possess similar skills, employers should desire more hours from their lower-wage part-time employees than those workers are willing to offer. This argument is reinforced by the Fair Labor Standards Act (FLSA) mandate of an overtime premium for hourly workers, which raises the cost of varying hours among full-time workers.
} 
exceed full-time wages. More generally, firms' use of part-time workers as a low-cost means of adjusting to variable and uncertain demand requires a relatively large supply of part-time workers. To the extent that there is limited mobility or substitution across labor markets (delineated by geography, occupation, and industry), equilibrium part-time gaps may vary across markets.

\section{B. Prior Evidence}

Few studies focus primarily on the wage gap between full- and part-time workers. But there are numerous studies in which part-time status is included as a control variable in a log wage equation. Such studies find a significant wage gap between full- and part-time workers following control for individual, job, and labor market characteristics typically included in standard data sets.

We do not attempt an exhaustive survey of the literature but, rather, focus on work most closely related to our analysis. Blank (1990) provides a comprehensive analysis identifying the extent and nature of part-time work and the wage penalty associated with it. Using the March 1988 CPS (for calendar year 1987) Blank finds a large part-time penalty using standard regression analysis. She attempts to control for unmeasured skill differences through both the use of instrumental variable methods and a selection model that accounts for the endogeneity of part-time status. She concludes that selection into part-time employment is important, but that estimates are highly sensitive to the method of analysis. Using a part-time instrumental variable (IV), the coefficient for women goes from -.21 using OLS to -.62 using IV. For men, the coefficient goes from -.30 to .82 . Taken literally, these estimates imply extraordinary part-time penalties for women and advantages for men. Blank attaches greater weight to the results of a selection model distinguishing between states of not employed, part-time, or full-time. Estimates here suggest a .17 log point part-time wage advantage for women and -.18 log point disadvantage for men. ${ }^{6}$ Given the reliance on a single cross-section of workers and the sensitivity of estimates to estimation method and specification, Blank is reluctant to attach undue weight to any particular set of estimates. She stresses that unmeasured worker and job heterogeneity are likely to be important and that outcomes differ across occupations.

Blank (1998) provides longitudinal evidence from the Panel Study of Income Dynamics (PSID), tracking workers as they move into and out of part-time employment. She concludes that individual unobservables are important predictors of transitions between part-time, full-time, and out of the labor force status. A short time series provides good predictions of future transitions, providing some support for our use of a panel with only two observations per worker. Although Blank is most concerned with explaining employment transitions, her work supports our conjecture that unmeasured person-specific skills and tastes

\footnotetext{
${ }^{6}$ Aaronson and French (2004) discuss difficulties in identifying causal effects of part-time work using IV or selection methods. They isolate exogenous shifts into part-time employment resulting from changes in Social Security rules.
} 
may be important determinants of wage differences between part- and full-time workers. Blank's finding that current work hours are highly correlated with past hours of work implies that part-time workers typically have accumulated lower levels of general and specific skills than full-time workers. Although parttime employment is common among married women (relative to men), it is often a transitional state, used by typically full-time workers during periods of unusually large family responsibilities, or as a form of intermittent employment by individuals frequently out of the labor force.

Studies within industries and occupations that include worker controls suggest that part-time penalties are small. Montgomery and Cosgrove (1995) compare part-time and full-time wages in child care establishments among teachers and aides, controlling for schooling and experience as well as establishment and occupation. They find a part-time wage disadvantage of about 8\%-9\% using OLS. Using IV or random effects estimation, they find effectively no wage gap among teachers and approximately a 7\% gap among aides. Recent work using child-care data from four large states finds no wage penalty for part-time child care workers following an accounting for selection (Mocan and Tekin, 2003). Similar or higher part-time wages are found among registered nurses (Hirsch and Schumacher 1995, among others).

As argued subsequently, the analysis in this paper attempts to address some of the issues raised in the work by Blank and others on part-time wages and employment. We do not model selection into parttime employment or strictly identify the causal impact of working part-time on wages. Large CPS panel data sets are used to better account for worker heterogeneity, however, and detailed occupational skill and working condition measures complement standard control variables. ${ }^{7}$

\section{Estimation Approaches}

The principal purpose of the analysis is to measure wage differences between similarly skilled workers across otherwise similar part-time and full-time jobs. The paper makes no attempt to estimate structural demand and supply models from which full- and part-time wages are equilibrium outcomes. The estimation strategy is straightforward. Reduced-form log wage equations are estimated, with the wages for part-time workers compared to those for full-time workers with similar measured characteristics. We extend the analysis by adding a large set of $O * N E T$ occupational skill and working condition variables, effecting a comparison of part- and full-time workers with similar characteristics in similar jobs.

\footnotetext{
${ }^{7}$ Other articles on part-time employment are less closely related to our work. Montgomery and Cosgrove (1993) find that child-care establishments reduce the use of part-time workers in response to higher nonwage benefits. Stratton (1994) finds that official statistics overstate the level of "involuntary" part-time workers. Elsewhere Stratton (1996) concludes that most part-time workers categorized as involuntary are likely to be such and more likely than other parttimers to switch to full-time employment. Barrett and Doiron (2001) examine the determinants of involuntary part-time employment and wage differentials using cross-sectional Canadian data. Fallick (1999) examines the relationship between changes in industry growth and changes in part-time employment.
} 
We then add information obtained from large multiple panels, in which each worker is observed in consecutive years. This information is first employed in the wage level analysis, wherein for each worker we control for her previous year's part-time status. If full-time and part-time workers differ in unmeasured skills, prior part-time status may be an important correlate of workers' current wages.

Longitudinal analysis is next used to measure wage changes for individuals as they move between part-time and full-time work. The comparison wage for each individual is now his or her own wage one year earlier, so that unmeasured worker attributes with a fixed effect on earnings are controlled (e.g., motivation, reasoning ability, preferences). The part-time penalty is estimated by the average wage change across individuals changing part-time status, relative to wage change among non-switching workers. We suggest that bias from endogenous switching can provide bounds on the longitudinal estimates. ${ }^{8}$

Separate wage equations are estimated for women and men. For ease of exposition, we use a simple dummy variable approach to measure the log wage differences associated with part-time status, conditional on controls (gaps are similar using separate equations). ${ }^{9}$ The form of the wage equation model is:

$$
\ln \mathrm{W}_{\mathrm{it}}=\mathrm{X}_{\mathrm{it}} \beta+\theta \mathrm{PT} \mathrm{T}_{\mathrm{it}}+\varepsilon_{\mathrm{it}}, \text { with } \varepsilon_{\mathrm{it}}=\Phi_{\mathrm{i}}+\mu_{\mathrm{it}}
$$

Here $\ln W_{i t}$ is the natural $\log$ of real hourly earnings of individual $i$ in year $t ; X$ is a vector of individual, job, and labor market characteristics defined at the individual level, with $\beta$ the corresponding coefficient vector (including an intercept); and $P T$ is a binary variable equal to one if the worker's principal job is part-time, with $\theta$ an estimate of the part-time log wage penalty. The error term $\varepsilon$ includes both a random component $\mu$ with mean zero and constant variance, and a worker-specific fixed effect $\Phi$. The inability to measure $\Phi$ directly causes estimates of $\theta$ in (1) to suffer from omitted variable bias if $\Phi$ is correlated with part-time status. If $P T$ and $\Phi$ are negatively correlated owing to lower unmeasured skills among part-time workers, estimates of $\theta$ are likely to overstate the part-time wage penalty.

Unmeasured worker attributes correlated with part-time status may be captured in part by including information on individual workers' part-time status in the previous year, $P T_{i, t-1}$.

$$
\ln \mathrm{W}_{\mathrm{it}}=\mathrm{X}_{\mathrm{it}} \beta^{\prime}+\theta^{\prime} \mathrm{PT}_{\mathrm{it}}+\Psi^{\prime} \mathrm{PT}_{\mathrm{i}, \mathrm{t}-1}+\varepsilon_{\mathrm{it}}^{\prime} \text {, with } \varepsilon_{\mathrm{it}}^{\prime}=\Phi_{\mathrm{i}}^{\prime}+\mu_{\mathrm{it}}^{\prime}
$$

Worker fixed effects remain in the error term, but these should be small to the extent that prior PT status captures acquired human capital and other forms of unmeasured skill. Thus, estimates of $\theta^{\prime}$ may provide a better measure than does $\theta$ of the part-time wage effect. Equation (2) uses current and prior part-time status,

\footnotetext{
${ }^{8}$ We do not consider selection into the labor force. Longitudinal estimates more closely approximate average treatment effects among the treated than among random draws from the population. We briefly report results from displaced workers, where the assumption of exogenous job (if not part-time status) change is reasonable.

${ }^{9}$ Earnings function parameters differ between part- and full-time workers, but wage gaps estimated using the dummy variable approach differ little from those based on separate equations by part-time status and evaluated at the means.
} 
$P T$ and $P T_{t-1}$, to describe four possible states. A more general form of wage equation (2) includes three rather than two dummies to account for the four states: part-time stayers PT[1,1], part-time joiners PT[0,1], part-time leavers PT[1,0], and the the omitted reference group of full-time stayers, PT[0,0].

Using multiple short panels with two observations per worker, one year apart, we estimate the following longitudinal wage equation (time subscripts in (1) are dropped):

$$
\Delta \ln \mathrm{W}_{\mathrm{i}}=\Delta \mathrm{X}_{\mathrm{i}} \beta^{\prime \prime}+\theta^{\prime \prime} \Delta \mathrm{PT}_{\mathrm{i}}+\Delta \varepsilon^{\prime \prime}{ }_{\mathrm{i}}, \text { with } \Delta \varepsilon^{\prime \prime}{ }_{\mathrm{i}}=\Delta \mu_{\mathrm{i}}
$$

Here, $\Delta$ represents the change operator between year $t$ and $t-1$ and $\theta^{\prime \prime}$ reflects wage changes between years $t$ 1 and $t$ for individuals as they switch between full-time and part-time status. The fixed effects estimator $\theta^{\prime \prime}$ is not precisely equivalent to $\theta^{\prime}$, but each should capture unmeasured skill differences between those switching part-time status and those who typically remain full-time (or part-time) employees.

While having important advantages, longitudinal analysis is not without shortcomings. The panel sample is not fully representative, measurement error in change variables can bias estimates of $\theta$ " toward zero, and, while addressing $P T$ endogeneity in (1), equation (3) assumes that changes in part-time status are exogenous. These issues are addressed subsequently, following presentation of the principal results.

Finally, an issue relevant to our analysis is the definition of part-time and full-time employment. The official BLS definition is based on whether a worker usually works 35 or more hours per week on all jobs. That is, part-time/full-time status is defined for individual workers and not for individual jobs (Nardone 1995). Because we are interested in pay differences to workers in full-time and part-time jobs we define part-time status (and pay) based on usual hours worked (and earnings) on each worker's principal job. A further question is whether 35 hours constitutes the appropriate breakpoint for defining part-time status. Papers by Hotchkiss (1991) and Averett and Hotchkiss (1996) explore the statistical justification for this definition, based on joint estimation of the labor supply choices of workers and wage determination among part-time and full-time jobs. The latter paper concludes that although men begin receiving a full-time premium at about 33 hours, white (black) women are not offered full-time wage premiums until roughly 37 (39) hours of work. Apart from the difficult methodological issues involved in statistically determining what constitutes part-time work, such analysis is limited by the fact that few workers report usual hours worked other than at hours amounts divisible by five or eight. We return to this issue subsequently.

\section{Data and Variables}

The primary data used in the paper are from the Current Population Survey (CPS) Outgoing Rotation Group (ORG) earnings files for September 1995 through December 2002. The CPS permits matching of individuals one year apart in the same month. We construct a large panel data set for the pairs of months September 1995/96 through December 2001/02. The match sample is constructed as follows. For 
each pair of months, one begins with rotation group 4 in the first year and rotation group 8 in the second year. Matches are created based on the use of a household identifier and record line number. As a check on the match, it is required that there be no change in gender or state, and that reported age change is within the interval $[0,2]$. Because the Census reinterviews households in fixed locations, those whose household moves or who move out of a household during the year are not in the sample. Young workers are most likely to be underrepresented (Peracchi and Welch 1995, Card 1996). ${ }^{10}$

Data issues dictated the choice of years. Changes to the CPS in 1994 improved measurement of average hourly earnings (among other things) and affected the number of workers categorized by BLS as part-time. Files for January 1994 through August 1995 are excluded for two reasons. First, changes in area identifiers during 1995 make it impossible to match households and create panels for the month pairs June 1994/95 through August 1995/96. Second, the public use CPS earnings files for January 1994 through August 1995 do not include valid flags for whether or not worker earnings have been imputed (Hirsch and Schumacher 2004). As will be shown, it is important that those with imputed earnings in either year 1,2, or both be excluded. This is a large number, comprising $37 \%$ of the potential panel sample among women and $39 \%$ among men. The analysis ends in 2002 owing to the adoption of a new set of detailed occupation codes in the CPS beginning in 2003. This makes it impossible to match O*NET data to the CPS in a time consistent manner before and after 2003.

The CPS ORG panel consists of non-student wage and salary workers, ages 16 and over (17 and over in the second year of each panel). Excluded are those who cannot be matched across years and who in either year are not wage and salary employees, are full-time students, have weekly earnings top-coded by the Census (at $\$ 1,923$ prior to and $\$ 2,885$ beginning in 1998) since wage change would be determined by the earnings assignment in the open-ended category, have an implied wage less than $\$ 2.00$ or more than $\$ 150$, have hours worked per week imputed, or have usual weekly earnings (or the hourly wage where appropriate) imputed. The wage variable, measured in 2002 dollars, is constructed as follows. Among workers reporting an hourly straight-time wage on the primary job, this is assigned as the wage if the person does not receive tips, overtime, or commission earnings. For all others, the wage is defined as usual weekly earnings on the primary job (which includes tips, overtime, and commissions) divided by usual hours worked per week. For those who are not assigned their straight-time wage and who designate that they have variable hours worked,

\footnotetext{
${ }^{10}$ Roughly half of each outgoing rotation group is eligible for a match. In forming the panel, .754 of all individuals in rotation group 4 are matched successfully to their records a year later. Among wage and salary workers ages 16+ in the intial year, .664 are matched and employed in wage and salary jobs the following year. Sample sizes then shrink as one deletes individuals who in either year are students, have top-coded earnings, have imputed hours worked, and, most significantly, have earnings imputed. These sample criteria are outlined below.
} 
weekly earnings are divided by hours worked last week.

To insure comparability between the wage level and wage change samples, the panel data set is used for estimation of both equations (1) and (2), with the levels equations based on second year observations for each worker. ${ }^{11}$ In addition to the part-time status variable, we include the following wage level control variables in $X$ : potential experience (the minimum of age minus schooling minus 6 or age minus 16) in quartic form (Murphy and Welch 1990; Lemieux 2003), education dummies (7 dummies included), marital status (2), race and ethnicity identifiers (4), foreign born, children in household (3), region (8), metropolitan size based on 1993 Census population counts (7), union membership, public, private not-for-profit, industry (12), occupation (11), and year (6). ${ }^{12}$ Also included are state-by-month unemployment rates and log employment changes (both using three month averages centered on the survey month).

$O * N E T$ is a new Department of Labor database intended to replace the Dictionary of Occupational Titles. $O^{*} N E T$ provides hundreds of numerical descriptors of occupations. Appendix Table A-1 provides details regarding $O * N E T$ and lists the variables (and their means) included in subsequent regressions. Below we summarize the occupational skills and working conditions measured by our $O * N E T$ variables.

Occupational Skill Requirements: Verbal skill measures include Oral Comprehension, Written Comprehension, Oral Expression, and Written Expression. Math skill variables measure Mathematical Reasoning, Number Facility, and Mathematics. Spatial measures are Spatial Orientation and Spatial Visualization. Problem Solving includes Problem Identification, Information Gathering, Information Organization, Synthesis/Reorganization, Idea Generation, Idea Evaluation, Implementation Planning, and Solution Appraisal. Technical Skill variables measure requirements for Operations Analysis, Technology Design, Equipment Selection, Installation, Programming, Testing, Operation Monitoring, Operation and Control, Product Inspection, Equipment Maintenance, Troubleshooting, and Repairing. System Skill measures include Visioning Systems, Perception, Identifying Downstream Consequences, Identification of Key Causes, Judgment and Decision Making, and Systems Evaluation.

Occupational Working Conditions: Six Hazard variables measure frequency times degree of injury for Radiation, Diseases/Infections, High Places, Hazardous Conditions, Hazardous Equipment, and Hazardous Situations. Seven Environmental variables are Working Outdoors, Distracting Sounds and Noise Levels, Extremely Bright or Inadequate Light, Exposure to Contaminants, Cramped Work Space or Awkward Position, Whole Body Vibration, and Prolonged Exposure to Very Hot or Cold. Five Strength

\footnotetext{
${ }^{11}$ As shown in Table 2, part-time wage gap estimates (following controls) using the full CPS ORG data set are moderately larger among women and smaller among men than are estimates from the panel sample.

${ }^{12}$ Marital status and children are intended to proxy differences in the valuation of home production and prior work experience. Because we estimate separate equations for women and men, these effects can differ by gender.
} 
variables are Static Strength, Explosive Strength, Dynamic Strength, Trunk Strength, and Stamina.

In the longitudinal analysis, variables included are year dummies and the following change variables: part-time status, union status, experience squared, number of children ages 0-17 in the household, broad industry, broad occupation, public employment, private nonprofit, the log of state employment, and the $O * N E T$ occupational variables. The unemployment rate is included in levels form. Several of the variables in $X$ are time invariant. By construction, region and city size do not change because households that move cannot be matched in the CPS panel. Other variables either cannot change by construction of the panel (e.g., gender) or are treated as invariant since recorded changes may result from error or have insufficient time to be reflected in earnings differences (e.g., race, ethnicity, schooling).

\section{Descriptive Evidence}

\section{A. Variable Means for Part-Time and Full-Time Women and Men}

A comparison of characteristics among part-time and full-time women and men is informative.

Table 1 provides means of selected variables from the matched CPS and $O * N E T$ sample for 1996-2002 (the second year for each worker pair). Part-time workers have lower wages and are more likely to be female, either young (among men) or old, and nonunion. Among women, part-time workers are more likely to be married with spouse present and have more children, while the opposite is seen among men.

The principal contribution of Table 1 is a comparison of means of the $O * N E T$ variables between part-time and full-time workers. Means are shown following aggregation into general categories. Appendix Table A-1 presents means for each of the individual $O * N E T$ variables included in the regressions. Because full-time and part-time (and female and male) workers within occupations are assigned identical values by $O * N E T$, differences in means result entirely from differences in occupational employment between part-time and full-time workers. To the extent that there exist within-occupation differences in skill requirements and working conditions, the mean differences reported in Table 1 understate the total part-time/full-time gap in skills and working conditions. ${ }^{13}$

Three patterns are evident in Table $1 .^{14}$ There exists a substantial gap in required occupational skills between part-time and full-time workers. Consistent with the thesis that skill differences explain much of the part-time wage disadvantage, full-time workers are found to be employed in occupations requiring higher levels of verbal, mathematical, problem solving, technical, and system skills. The exception is spatial skills, where little difference is found. A second pattern is that the part-time gap in occupational skill requirements

\footnotetext{
${ }^{13}$ Hersch (1998) shows that it is important to include gender-specific values of job attributes in measuring compensating differentials. Inability to distinguish attributes by gender or part-time status is likely to understate their wage impact.

14 The same three patterns are evident when we match to the CPS occupational skill and working condition measures from the Dictionary of Occupational Titles, a predecessor to $O * N E T$.
} 
is systematically larger for male than female workers, consistent with the larger part-time wage gap among men than women. Although the gender wage gap is not a focus of this paper, note that $O * N E T$ skill requirements are not systematically lower for women than men. Among part-time and full-time workers, women are employed in occupations requiring somewhat higher levels of verbal, math, and problem solving skills than are men, and lower levels of spatial and technical skills.

A third pattern evident from Table 1 is that there is little systematic difference in working conditions between the occupations in which part-time and full-time workers are employed. In contrast to job skills, working conditions appear unlikely to account for the wage gap. If anything, part-time women are employed in occupations with somewhat greater hazards, strength requirements, and environmental risks. The pattern among men is mixed, with full-time men in jobs with somewhat greater hazards and environmental risks, but not strength (the latter may not be a clear disamenity for men).

\section{B. The Distribution of Hours Worked and Wages}

Prior to the formal analysis, the frequency distributions of usual hours worked per week (on the principal job) and mean wages by hours worked are examined. In order to insure reasonable sample sizes at hours worked other than 40 hours, we rely on the full CPS-ORG earnings files for September 1995-2002. The hours distributions for women and men can be briefly summarized (it is not shown in order to save space). First, there is a heavy concentration of workers reporting 40 usual hours worked per week, 53\% among women and 57\% among men. Second, the hours distribution among women is more dispersed than for men and contains more low-hour and fewer high-hour observations. And third, there exist "spikes" or "heeping" at intervals divisible by five, a common survey phenomenon. ${ }^{15}$ If we examine the distribution of "hours worked last week" we obtain a more dispersed distribution with fewer workers reporting exactly 40 hours, $42 \%$ among women and $45 \%$ among men. ${ }^{16}$

Figures $1 \mathrm{a}$ and $1 \mathrm{~b}$ show mean wage rates by hours worked between 20 and 60 hours. Despite the large overall sample, there is noise in both tails of the distribution and at hour intervals not divisible by five, owing to few workers reporting such hours and some unknown degree of measurement error among those for whom an implicit wage (weekly earnings divided by hours) is calculated and who report very low and high work hours. Most relevant for our analysis is the finding of a sharp break in wages around 35 hours, rather than a gradual increase beginning at low levels of hours worked. ${ }^{17}$ Although a jump is evident for

\footnotetext{
${ }^{15}$ There are also significant numbers of workers at hour intervals divisible by eight $-24,32$, and 48 . This raises an issue not addressed in this paper. Is it low weekly hours or daily hours that are associated with lower part-time wages? Lettau (1997) examines this issue.

${ }^{16}$ An even smoother distribution of hours worked would no doubt be found using time diary surveys.

${ }^{17}$ For an analysis of this issue, see Hotchkiss (1991) and Averett and Hotchkiss (1996).
} 
women and men, the unadjusted full-time wage advantage is clearly larger among men than women.

The wage break at 35 hours provides justification for following the convention of defining part-time status as a binary rather than continuous variable, with the breakpoint being less than 35 versus 35 or more hours worked per week. That being said, wages tend to increase with respect to hours among full-time workers, particularly men (absent controls). This is most evident if one focuses on mean wages at the rounded hours values (i.e., 40, 45, 50, etc.), where sample sizes are largest. Mean wages are substantially higher at the rounded hours values than elsewhere. Why this should be so is not clear. Because Figures 1a and $1 \mathrm{~b}$ present wages absent control for worker or job characteristics, inferences about how conditional wages vary with hours must await multivariate analysis.

\section{Wage Level and Longitudinal Estimates of the Part-Time Penalty}

\section{A. Wage Level Estimates of the Part-Time/Full-Time Wage Gap}

Table 2 provides wage level regression estimates of the part-time gap using the second year observation for each worker in the CPS panel (the years 1996-2002). Longitudinal estimates, shown subsequently in Table 3, are based on wage change regressions for 1995/96-2001/02.

As seen in line A-1, the part-time/full-time log wage differential, unadjusted for worker, job, or labor market characteristics is -.219 log points (19.7\%) for women and -.464 (37.1\%) for men. The unadjusted differentials are the benchmark figures to be used in evaluating how much of the part-time gaps are accounted for by measured characteristics and unmeasured worker heterogeneity.

In line A-2, estimates of the part-time gap are based on a standard wage level equation with controls for individual and location characteristics, but not industry or occupation. Estimates of $\theta$ are -.175 and -.328 for women and men, respectively. In line 3 we add industry dummies, reducing estimates of $\theta$ to -.133 for women and -.269 for men. These results imply that $39 \%$ of the female gap (1-.133/.219) and $42 \%$ of the male gap (1-.269/.464) are accounted for by standard control variables.

Addition of occupation dummies (line A-4) reduces estimates of the wage gap, to -.104 for women

and -.218 for men. Estimates in A-4 are based on a relatively dense specification using standard information available in micro data sets. Line A-5 substitutes the $O * N E T$ occupational variables for the broad occupation dummies. These reduce the gap more than does the inclusion of occupation dummies. Our "preferred" wage level estimate of the part-time gap is shown in line A-6, with inclusion of all CPS and $O * N E T$ variables. Estimates of $\theta$ are -.087 for women and -.191 for men. Controlling for measurable personal, location, and job characteristics accounts for about 60 percent of the total part-time wage disadvantage among both women and men (i.e., 1-.087/.219=.60 and 1-.191/.464=.59, respectively). 
using the full CPS-ORG sample for September 1995 through 2002 (imputed earners are excluded, although this has no effect on wage level results). The raw part-time wage gaps (no controls) are somewhat larger for the full sample than the panel sample. There is little difference in the estimates with controls, however, the estimated part-time penalty using the full versus the panel sample being .01 log points higher among women and .02 lower among men. The implication is that results in this paper using the panel sample are roughly representative of what would be obtained with the full CPS.

We next address whether the part-time wage gap varies with the level of hours. Table 2 provides estimates of wage differences associated with alternative levels of hours worked, based on inclusion of five dummy variables (40 hours is the omitted category). Line C-1, based on a regression absent controls, summarizes the information pictured in Figures $1 \mathrm{a}$ and $1 \mathrm{~b}$. The part-time gap is roughly similar between 124 and 25-34 hours worked, while among full-time workers wages are higher and tend to increase with hours worked. Following control for worker and job characteristics (line C-2), the relationship between hours and wages is much weaker. There is no substantial difference in wages among those working 1-20 versus 21-34 hours. Differences between those working 35-39, 40, and 41-49 hours are modest.

A bit puzzling is that women and men reporting 50 or more usual hours per week have hourly earnings about 3-4\% lower than those working 40 hours. For those whose wage is measured implicitly (i.e., weekly earnings divided by weekly hours), the lower wage may result from mismeasurement of hours among those some with high hours, or because those working long hours have relatively low disutility from work and do not require high wages, ceteris paribus. Because those reporting very high hours constitute a small portion of the workforce, these issues are not explored further. The results reported in C-2 suggest that use of a single dummy is a reasonable as well as convenient strategy for approximating the part-time wage gap.

Section D of Table 2 provides estimates related to equation (2), in which information on prior as well as current part-time status is used. The coefficient on current part-time status is sharply reduced once one accounts for whether a worker's primary job was part-time one year ago. Prior part-time status has a far larger impact than does current status on the observed current wage. Focusing on regression results with full controls, having a part-time job in the current year decreases women's wages by only -.013 log points, as compared to a coefficient of -.108 for prior part-time status. This implies that as compared to full-time workers in both periods, workers who are part-time in both year have wages -.121 lower, while workers who are currently full-time but were part-time the previous year, have full-time wages -.108 lower than among full-time stayers. Among men, the estimated wage penalty from current part-time status is -.092. Workers who are part-time in both years have wages -.263 lower than men full-time in both periods, while workers who are currently full-time but were part-time the prior year have full-time wages -.171 lower. For both 
women and men, prior part-time work (and presumably lower human capital accumulation) leads to a substantially larger wage penalty than does the part-time status of the current job.

A more general specification separates part-time stayers, joiners, and leavers, each being compared to full-time stayers. Among women, the penalty for current part-time work (the coefficient among joiners) is -.059 , small as compared to the -.147 wage penalty realized by full-time workers who were part-time the prior year. The -.113 penalty for part-time stayers using this more general specification is a bit lower than seen above. Likewise, male full-time workers who were previously part-time suffer a larger wage penalty than do those currently working part-time but who were previously full-time (-.190 versus -.114). Male parttime stayers suffer a sizable -.252 wage penalty as compared to full-time stayers.

It was noted that workers with imputed earnings in either year are excluded from the analysis. Hirsch and Schumacher (2004) show that there exists bias toward zero (what they term "match bias") for coefficients on attributes that are not a Census criterion on which earnings donors are matched to nonrespondents. This includes characteristics such as union status, industry, foreign-born, etc. The bias can be roughly approximated by the proportion of workers with imputed earnings, currently about $30 \%$ in the CPS. Included in the hot deck match criteria, however, are eight hours-worked categories, so all full-time (part-time) nonrespondents are assigned the earnings of a full-time (part-time) donor. There is no mismatch on current part-time status, and wage level estimate of the sort seen in panel A of table 2 are largely unaffected by inclusion of imputed earners. However, wage level analysis using prior year part-time status, or longitudinal analysis examining wage changes, identifies the part-time wage effect based on wage differences associated with those changing part-time status. There is a donor mismatch for switchers, with part-time joiners who do not report earnings in year 1 likely to be assigned the earnings of a full-time stayer and those not reporting earnings in year 2 likely to be assigned the earnings of a part-time stayer. Just the opposite is true for leavers. In short, assigned earnings in the sample of imputed earners fails to net out fixed effects, with estimates being biased toward the standard wage level result.

The effect of imputation bias can be readily seen in panel $\mathrm{E}$, where we include wage equation results for the sample of workers with earnings imputed in at least one of the years. ${ }^{18}$ These results provide incorrect inferences, with prior part-time status now appearing to have little impact on the wage as compared to current part-time status, the opposite of that seen among workers who report earnings.

\section{B. Longitudinal Estimates of the Part-Time/Full-Time Wage Gap}

\footnotetext{
${ }^{18}$ Were the focus of this paper on imputation bias, we would distinguish among those with imputed earnings in year 1,2 , and both years, cross-classified by their part-time status in years 1 and 2. For purposes here, the only point being made is that there exists substantial bias and that imputed earners should be excluded from the analysis.
} 
Initial Results. Longitudinal estimates of the part-time wage gap, $\theta^{\prime \prime}$, are based on the wage changes of workers switching into and out of part-time status. Table 3 provides estimates of $\theta^{\prime \prime}$ (i.e., the $\triangle P T$ coefficients) from wage change equations for the pairs of years 1995/96-2001/02. Estimates of $\theta$ " vary relatively little with respect to specification density since worker skills are largely captured by the fixed effects. Thus, we present results from only two specifications, one with no controls and the other with a full set of controls. Note that wage change results apply strictly only to the population likely to be at the margin between part-time and full-time work, in effect providing estimates of a "treatment effect" among the treated. For some purposes, this may be the group in whom we are most interested. But even if we would like to estimate wage gaps for randomly selected workers (most of whom are unlikely to switch part-time status), longitudinal estimates may be superior to those from standard wage level equations. Although neither analysis accounts for selection into part-time employment, the longitudinal analysis does account for worker heterogeneity, which in this application is important. ${ }^{19}$

The obvious result seen in Table 3 is that there is little wage change associated with change in parttime status. Absent controls, the $\triangle P T$ coefficient $\theta^{\prime \prime}$ is .005 for women and .004 for men - close to zero and of the "wrong" sign. With a full set of controls, the estimate of $\theta$ " is .015 for women and .019 for men. The apparent inference from these results is that all of the part-time wage disadvantage can be accounted for by what are lower worker-specific skills among part-time than full-time workers, with some of these skills not measured by standard variables. Before accepting this sweeping (and surprising) conclusion, it is important that the longitudinal results be probed in some detail. We turn to this task below.

Endogenous Job Change, Bias, and Symmetry Between Wage Gains and Losses. Longitudinal results presented in Table 3, line A, impose symmetry between the wage effects from moving into and out of part-time jobs. In line B, this restriction is relaxed, with separate wage changes estimated for full-time stayers (the reference group), part-time stayers, part-time leavers, and part-time joiners. These results echo those above - those switching part-time status display small wage changes, with the direction of change being inconsistent with the presence of penalties for part-time work. A result to note is the coefficient on initial part-time status, indicating that part-time stayers have lower wage growth than do full-time stayers, -

\footnotetext{
${ }^{19}$ As emphasized by Aaronson and French (2004), attempts at accounting for selection using IV and selection models have produced a wide range of results, some of which are counterintuitive. Aaronson and French estimate wage effects based on changes into part-time employment among older workers induced by Social Security rule changes, finding a part-time penalty for men but not women. An earlier version of my paper examined changes in part-time status among displaced workers, the logic being that exogenous job change is more likely to result in an exogenous change in parttime status. The analysis showed little wage change among women, but modest part-time penalties for displaced men. Part-time employment is more likely to be involuntary among displaced workers, both in pre- and post-displacement jobs. Farber (1999a) provides a detailed analysis of alternative employment arrangements among displaced workers.
} 
.003 less among women and a more substantial -.013 among men (mean wage growth among the full sample is .036 for women and .037 for men) ${ }^{20}$ The slower growth in wages is consistent with standard human capital theory and suggests that part-time wage gaps observed in cross-sectional analysis should increase with age (we later return to this question). Worker heterogeneity, which leads to longitudinal part-time gaps of effectively zero, may reflect to no small degree a lower accumulation of on-the-job skills.

In order that longitudinal estimates of $\theta^{\prime \prime}$ be unbiased, changes in part-time status must be exogenous. The change in part-time status, however, is likely to be correlated with wage change. Such bias could be advantageous in this analysis because the direction of bias can be signed and allows one to put bounds on the part-time wage gap. Endogenous job switching is positively related to wage change, all else the same. ${ }^{21}$ The probability of workers switching from part- to full-time employment should be high for those with an unusually low part-time wage and/or unusually high full-time wage opportunity, thus overstating the expected gain of moving to a full-time job for an exogenous job switcher. Using similar reasoning, the probability of switching from full- to part-time employment is high for those with an unusually low full-time wage and/or unusually high part-time wage opportunity, thus understating the expected loss of moving to a part-time job for an exogenous switcher. Bias is positive for both groups, but in opposite directions in absolute value, away from zero for PT-FT gains and toward zero for FT-PT losses.

Having argued above that longitudinal estimates of the part-time penalty can potentially be bounded, results shown in Table 3 indicate that there exists nothing to bind in this case, given the "incorrect" signs obtained for part-time joiners and leavers. The "overstated gain" from PT-FT transitions is estimated to be negative; the "understated loss" from a FT-PT transition is estimated to be positive. Whatever is motivating part-time change, it appears to be more than wages. Given the trivial magnitude of the estimates, perhaps the only point worth emphasizing is that there exists little average wage change among workers switching into or out of part-time jobs.

Earnings Imputation and Bias in Longitudinal Estimates. Before probing the longitudinal results further, it is worth presenting results based on the excluded sample of workers whose wages are imputed in at least one of the years. Imputed workers are assigned the earnings of a donor with the same part-time status, but not workers who are switching status. Thus, these longitudinal estimates are biased toward standard wage level results since worker fixed effects are not netted out. Results are shown in line C of

\footnotetext{
${ }^{20}$ For ease of interpretation, a "PT-Initial Period" rather than a "part-time stayer" dummy is included (either captures the wage change for part-time relative to full-time stayers). The part-time leaver dummy, therefore, measures directly gains from switching to full-time employment, as compared to remaining part-time.

${ }^{21}$ Changes in part-time status also are influenced by changes in family responsibilities, health shocks, pension and Social Security benefits and rules, and the like.
} 
Table 3. We focus on the models with full controls. As opposed to effectively zero wage change associated with part-time status change among those who report their own earnings, the imputed sample displays apparent wage changes associated with changes in part-time status. Among women, those switching into part-time jobs display an apparent -.07 wage penalty, while those switching to full-time appear to realize a .05 wage gain. Among men, the apparent wage loss is -.18 among those moving to part-time jobs and the wage gain .13 among those moving to full-time jobs. Inclusion of imputed earners in longitudinal analysis leads to erroneous inferences, biasing results toward standard wage level results and causing researchers to overstate the magnitude of part-time penalties among workers switching part-time status. ${ }^{22}$

Industry/Occupation Switchers and Misclassification Error. This section addresses two seemingly distinct issues. Concern about measurement error in the part-time change variable leads us to separate parttime switchers on the basis of whether they change detailed industry and/or occupation. One conclusion from this analysis is that misclassification error is not driving the longitudinal results. A second conclusion is that there are significant part-time penalties for part-time switchers who change industry and occupation.

Misclassification error in right-hand-side change variables is likely to bias coefficient estimates toward zero. If there were a large number of workers incorrectly classified as changing part-time status relative to the number of true status changers, bias in $\theta^{\prime \prime}$ would be severe. Our expectation is that misclassification of part-time changers should be low, but it is important that the issue be examined. Past research finds that bias on longitudinal estimates of the union wage effect is serious (Freeman 1984, Card 1996). Hirsch and Schumacher (1998) show that misclassification of union status change is reduced substantially by focusing on union switchers who also change detailed occupation and industry. These workers are most certain to have switched employers and thus most likely to be true union switchers (one cannot directly measure whether a worker has changed employers between rotation groups 4 and 8 ).

In line $\mathrm{D}$ of Table 3, results are presented from models interacting $\triangle P T$ with dummies designating the four groups of industry/occupation changers. Industry change is recorded with relatively little error, whereas occupation is frequently recorded as changing, even among those not changing employers during the year (Polivka and Rothgeb 1993). Workers recorded as changing both industry and occupation are most likely to be true job and part-time switchers. Those recorded as changing industry but not occupation are also likely to be true switchers. Thus, estimates of the part-time wage effect for these two groups are least

\footnotetext{
${ }^{22}$ Earlier versions of this paper included workers with imputed earnings in the longitudinal analysis, thus biasing results. For the same reason, analysis by Aaronson and French (2004), who utilize several longitudinal data sets, including the CPS-ORG, is likely to overstate part-time wage penalties.
} 
likely to be biased toward zero by misclassification error. ${ }^{23}$

Substantially different part-time wage effects are found for workers switching both occupation and industry and those who do not. Focusing on the $\triangle P T$ for industry and occupation changers in the specification with full controls (line D-2), we find a -.050 log point wage change associated with the change in part-time status among women and a -.057 change among men. In short, there exists a nontrivial part-time penalty for workers switching industry and occupation, albeit a wage penalty considerably smaller than those suggested by standard wage level analysis (about -.10 for women and nearly -.20 for men). Thus, even for the group of job switchers for whom we observe the largest part-time penalties, accounting for worker heterogeneity sharply reduces estimates of the penalty, by roughly half for women and by more than twothirds for men. Longitudinal estimates of $\theta^{\prime \prime}$ based on part-time status switchers changing detailed industry but not occupation are effectively zero for women and positive for men. Because industry is recorded relatively accurately, there should be little bias in these estimates. Positive coefficients are obtained for part-time switchers recording changes in occupation-only or neither industry nor occupation.

Misclassification error is unlikely to explain the large differences in estimates among the different groups of part-time switchers, and cannot explain large positive coefficients (as opposed to coefficients close to zero). ${ }^{24}$ Rather, estimated wage change differences appear to be real. Although it is not clear whether one should focus on the effectively zero average wage change among all changing part-time status, or the moderate part-time wage penalty realized by occupation and industry switchers, a similar broad conclusion emerges. Most of the very large part-time wage gap is accounted for by measurable worker and job characteristics. Of the remaining gap, much of it is accounted for by unmeasured worker-specific skills.

We are left without a convincing explanation for why there is a wage effect associated with changing part-time status for workers changing industry and occupation, but not for other part-time changers. The answer is not that it results from a greater loss in specific human capital when there is an industry and occupation change. Workers who remain full-time (or part-time) across years but change occupation and industry also lose specific capital. Note also that being held constant are changes in broad industry and occupation, as well as dummies designating whether a worker changed industry and

\footnotetext{
${ }^{23}$ Separate 0/1 dummies are included in line D-1, controlling for whether workers change detailed industry and occupation, industry only, and occupation only (these coefficients are effectively zero). Line D-2 adds variables measuring changes in broad industry and occupation (i.e., dummies in difference form, with values of $-1,0$, and 1). ${ }^{24}$ The conclusion that bias from misclassification of part-time change is small stems from several sources. As noted, the CPS industry variable is recorded with far greater accuracy and consistency than is occupation, yet industry-only switchers have estimates of $\theta^{\prime \prime}$ dissimilar to those changing industry and occupation. Second, reported hours changes among those classified as switchers are relatively large. Third, restricting the analysis to those with 38 plus hours and 32 or fewer hours has little effect on results.
} 
occupation, industry only, or occupation only (coefficients on these three dummies are effectively zero).

The closest we come to a satisfactory interpretation is speculation that workers switching part-time status, occupation, and industry are workers most likely to be shifting into or out of careers. That is, we are observing wage changes among workers moving from low-paid non-career jobs into higher-paying career jobs, and workers moving out of full-time career jobs to part-time jobs in a different occupation and industry. What is being called a penalty for part-time hours (or premium for full-time hours) is in part a wage differential associated with movement between career and non-career jobs. ${ }^{25}$ These results complement findings by Aaronson and French (2004), who find substantial wage losses among older men moving into part-time employment at the time of Social Security eligibility. Below, we examine how parttime wage penalties vary with age or potential experience.

\section{Additional Evidence: Experience, Students, and Nonwage Benefits}

This section provides additional analysis on part-time compensation. We explore the relationship between the part-time penalty and experience, examine the sensitivity of wage gap estimates to the inclusion of students, and summarize evidence on nonwage benefits among part-time and full-time workers.

\section{A. Are Unmeasured Skills Experience and Tenure Related?}

Longitudinal analysis indicates that much of the observed part-time wage gap is due to worker heterogeneity unmeasured in standard analysis. Part-time workers accumulate less human capital than fulltime workers over the same years of potential experience. As shown by Blank (1998) using the PSID, hours worked by individuals are correlated across time. A recent paper by Manning and Robinson (2004) draws a similar conclusion using British panel data. Part-time wage gaps are small at entry, but part-time workers have intermittent participation and substantially slower wage growth than do full-time workers. Part of what is typically interpreted as a part-time penalty reflects lower levels of accumulated human capital owing to fewer hours of prior work (i.e., a higher frequency and duration of part-time and non-employment spells).

To examine this issue, we first return to the wage level analysis presented in Table 2. Estimated are equations identical to those shown in line A-6, except that the slopes of wage-experience profiles are allowed to vary by part-time status. As expected, a significantly flatter profile for part-time workers is found, implying that the part-time wage gap grows with respect to potential experience. An instructive exercise is to assume that all differences in the slopes of experience profiles between part- and full-time workers result from differences in human capital accumulation. The part-time penalty is then measured by

\footnotetext{
${ }^{25}$ Neal (1999) provides an operational definition of "career" based on whether job changes among young workers involve changes in occupation. A referee suggests that geographic movers, not included in CPS panel samples, are most likely to resemble industry and occupation changers with relatively large wage changes.
} 
the coefficient on $P T$ in a specification that includes interactions between $P T$ and potential experience (and its square). Our estimate of $\theta$ in the wage level model (line 6 of Table 2) is -.087 for women and -.191 for men absent interaction terms. Inclusion of a quadratic in experience, separately and interacted with $P T$, drives the $P T$ coefficient $\theta$ toward zero, -.025 for women and -.075 for men. ${ }^{26}$ The coefficients on the $P T$ experience interaction terms indicate a part-time gap that increases with experience at a declining rate (a flatter and less concave wage profile among part-time workers). Accepting the (strong) assumption on which this analysis is based, estimates of $\theta$ imply a small causal part-time penalty for women and a moderate penalty for men, the same conclusion reached in the earlier analysis.

To see in detail how part-time wage gaps vary with potential experience (or age), we use the full CPS ORG (rather than panel) for September 1995 through 2002. We estimate the part-time wage gap at each year of potential experience from 0 to 48 (the last group including those with 48 or more years). The estimates are from a specification with full controls (equivalent to line 6 in Table 2) and are based on the coefficients on $P T$ interacted with dummies for each year of potential experience. As before, full-time students and those with imputed earnings are excluded. Unlike the panel analysis, we include all outgoing rotation group workers and not just matched panels, and include those with top-coded earnings. Results are shown in Figure 2. What is readily evident from the figure is that part-time wage gaps are small among young workers, but increases with potential experience, albeit at a declining rate. Effectively, the part-time wage gap simply mirrors the earnings-experience profile. A substantial portion of the part-time wage gap is associated with lower skills, due in no small part to lower levels of accumulated human capital over the lifecycle. As seen throughout this paper, the part-time gap is substantially larger among men than women (stated alternatively, the gender wage gap is most substantial among full-time workers).

A measure related to accumulated work experience and specific training is tenure, which measures years with one's current employer (for an analysis of the tenure literature, see Farber 1999b). In Table 4, we present calculated means of tenure by part-time status using the April 1993 CPS Benefit Supplement. Among women, part-time workers average only 4.5 years tenure with their current employer, compared to 7.5 years for full-time workers. Among men, the absolute and relative tenure gaps are larger, part-time and full-time workers averaging 3.2 and 8.8 years of tenure, respectively, consistent with the larger part-time wage gap among men than women. Because part-time and full-time workers differ in age, we also estimate $\log$ tenure equations, holding constant years of potential experience and other worker characteristics. As seen in Table 4, among part-time women, tenure is -.46 (37\%) lower than for full-time workers, controlling

${ }^{26}$ Using a quartic in potential experience, plus $P T$ interactions with each of the four terms, we obtain $\theta$ estimates of -.019 for women and -.100 for men. 
for potential experience and its square, and is -.31 (27\%) lower following control for individual characteristics, location, union membership, firm size, industry and occupation dummies (absent firm size dummies the part-time coefficient is -.32). A stronger pattern is found among men, with a part-time coefficient of -.60 (45\%) controlling for experience and -.40 (33\%) following a full set of controls (-.41 absent firm size). Part-time workers possess lower firm-specific experience than do full-time workers with similar characteristics in similar industries and occupations. Such evidence reinforces the conclusion that skill differences account for a substantial portion of the part-time wage disadvantage.

\section{B. Students}

The analysis presented to this point has excluded workers enrolled full-time in school in either year $t$ or $t-1 .{ }^{27}$ Among those in the labor force, school attendance is likely to increase the labor supply of part-time relative to full-time workers, particularly in jobs most complementary to students' schedules and preferences. Moreover, students are sometimes concentrated in labor markets where the supply (and, to a lesser extent, demand) for part-time work is large (i.e., so-called college towns).

Our interest here is not the magnitude of the part-time penalty for students but, rather, whether previous estimates would have differed appreciably had the analysis included students. We reestimate the wage equations shown in Tables 2, including those previously excluded who were full-time students in either year $t$ or $t-1$ (results are summarized but not shown). With students included, both the female and male unadjusted part-time gaps increases substantially, since absent controls young student part-time workers are being compared to older full-time workers. Among women, the unadjusted part-time wage gap increases from -.219 absent students (shown in Table 2, line A) to -.276 with students. Among men, the unadjusted gap increases from -.464 to -.595 .

In wage level regressions with controls (equivalent to lines A-2 through A-6), the student effect is minimal, having little effect on part-time gap estimates for women, while decreasing slightly the male gaps. Focusing on specification A-6 (full controls), the part-time gap estimate remains at -.087 among women once students are included. Among men, the gap changes from -.191 absent students to -.173 with students.

Young people attending school constitute an important segment of the part-time labor force. But because they face severe constraints on their time and mobility, wages realized by students need not be representative of part-time wages available to non-students. That being said, none of the conclusions reached in the paper would be appreciably different were the analysis expanded to include students.

\section{Nonwage Benefits}

\footnotetext{
${ }^{27}$ Excluded are full-time students less than age 25. School attendance questions are asked of respondents ages 16-24.
} 
Analysis in this paper has focused on wage differences between part-time and full-time workers. Even if there were no wage penalty, there would exist a compensation penalty owing to differences in benefits. Available data do not readily permit incorporation of benefits into a compensation equation. CPS data provide information on receipt of benefits by individual workers, but not their dollar cost (or value). Establishment surveys conducted by BLS provide information on costs of benefits to employers, but do not permit matching these benefits to individual workers for whom we have measures of age, schooling, and other wage-related characteristics.

All available evidence indicates that part-time workers are substantially less likely to receive nonwage benefits than are full-time workers. Lower receipt rates are seen in household data from the March CPS (Snider 1995; Farber and Levy 2000) and in BLS establishment surveys (U.S. BLS, 2003). The establishment surveys not only provide information on pension coverage and health insurance, but also on paid time off (holiday, vacation, personal, funeral, jury, military, sick, family leave), other forms of insurance (disability, dental, life), and tax-deferred earnings arrangements. Differences between part-time and full-time workers in virtually all benefit categories are substantial.

Differences in benefit coverage rates tell us little about cost differences or the magnitude of the parttime hourly compensation gap. The BLS's Employer Costs for Employee Compensation (ECEC) program measures costs, although such data cannot be linked to individual workers and their characteristics. In a paper using March 1994 ECEC data, BLS economist Michael Lettau (1997) calculates part-time wage and compensation differentials, based on 567 part-time and 571 full-time observations on jobs within the same establishment and 3-digit occupation. Lettau finds a -.164 part-time log wage gap for private nonunion jobs and a -.227 log compensation differential. Although Lettau is comparing part-time and full-time workers in the same occupation and establishment, he cannot control for individual differences in schooling, age or experience, tenure, gender, race, and the like. The evidence in this paper shows that the part-time gap is accounted for in no small part by past work experience and other individual differences in worker skills. This leads us to believe that the true part-time penalty is substantially less than evident from ECEC figures.

The .06 increase in the gap found by Lettau following addition of benefits is of particular interest. This difference may provide an upper-bound measure of how our gap estimates would change were we able to measure total compensation as opposed to wages in the CPS. Just as part-time wage gap estimates fall sharply as one controls for skill, it is reasonable that benefit estimates would fall were one able to control adequately for skill. ${ }^{28}$ We previously concluded that part-time/full-time wage gaps for similar workers in

\footnotetext{
${ }^{28}$ Because of unmeasured skills, among other reasons, the benefits literature is generally unable to confirm the clear-cut theoretical prediction of a tradeoff between wages and benefits. A notable exception is a recent paper by Olson (2002).
} 
similar jobs is close to zero among women and small or modest among men. Were we to add an "upperbound" .06 to these estimates to obtain compensation penalties, these gaps would be nontrivial in magnitude, yet far lower than are unadjusted part-time wage or compensation differentials.

\section{Conclusions}

This paper has examined the role of worker-specific skills and occupational skill requirements on what are large differences in wages between part-time and full-time workers. Wage level analysis shows that much of the part-time wage disadvantage for women and men can be accounted for by measurable differences in workers and jobs. If one controls for a worker's part-time status in the prior year, there remains only a small penalty from current part-time employment. Longitudinal estimates indicate little if any part-time wage penalty for women, who comprise two-thirds of part-time workers, but a modest penalty among men. ${ }^{29}$ Substantive wage gaps are found only among workers changing detailed industry and occupation in addition to part-time status. Part-time wage penalties are small early in women's and men's work lives, but rise over time, with workers most likely to be observed in part-time employment accumulating relatively less human capital.

It is widely accepted that employer fixed costs and a large supply of workers preferring part-time hours lead to lower compensation in part- than in full-time jobs. The analysis here demonstrates that much of the sizable part-time wage disadvantage stems from differences between part- and full-time workers in job characteristics, preferences and, most importantly, accumulated skills. For similar workers in similar jobs, part-time wage penalties are on average very small, leading to a modest gap in total compensation. ${ }^{30}$

Widespread part-time work does not appear to result from any systematic failure by firms to create full-time jobs, given that most part-time workers are not seeking full-time work (i.e., they are "voluntarily" part-time). In short, the wage evidence presented in this paper appears broadly consistent with what one would expect from the interaction of labor demand and supply in roughly competitive labor markets.

\footnotetext{
${ }^{29}$ We have labeled the wage gap a part-time penalty, found to be relatively small, particularly among women. One could alternatively refer to a "full-time reward" and ask why women do not realize the same reward as men. This shifts the focus toward an examination of the gender wage gap, the subject of a large body of research. Our analysis complements this literature, reinforcing its traditional focus on gender wage differences among full-time workers. ${ }^{30}$ Although not the subject of this paper, an implication of a weak hours-to-wage effect is that it lessons the need for simultaneous equations methods in labor supply studies (i.e., the wage-to-hours effect). Lundberg (1985) and Aaronson and French (2004) analyze this issue.
} 


\section{References}

Aaronson, Daniel and Eric French. "The Effect of Part-Time Work on Wages: Evidence from the Social Security Rules.” Journal of Labor Economics, Vol. 22 (April 2004): 329-52.

AFL-CIO Public Policy Department. Part-Time Work, Full-Time Bills: The Problems of Part-Time Employment, Washington, August 1998.

Averett, Susan L. and Julie L. Hotchkiss. "Discrimination in the Payment of Full-Time Wage Premiums." Industrial and Labor Relations Review, 49 (January 1996): 287-301.

Barrett, Garry F. and Denise J. Doiron. "Working Part-Time: By Choice or By Constraint." Canadian Journal of Economics 34 (November 2001): 1042-65.

Blank, Rebecca M. “Are Part-time Jobs Bad Jobs?” In A Future of Lousy Jobs? The Changing Structure of U.S. Wages, edited by Gary Burtless. Washington, D.C.: The Brookings Institution, 1990.

. "Labor Market Dynamics and Part-Time Work." Research in Labor Economics 17 (1998): 57.

Card, David. "The Effect of Unions on the Structure of Wages: A Longitudinal Analysis.” Econometrica 64 (July 1996): 957-79.

Christensen Sethi, Rachel, "Contingent Workers and Alternative Work Arrangements, 1995-2001." EBRI Notes, Vol. 23, No. 1, January 2002.

Euwals, Rob and Maurice Hogerbrugge. "Explaining the Growth of Part-Time Employment: Factors of Supply and Demand.” IZA Discussion Paper No. 1124, April 2004.

Fallick, Bruce C. "Part-Time Work and Industry Growth.” Monthly Labor Review 122 (March 1999): 22-29.

Farber, Henry S. "Alternative and Part-Time Employment Arrangements as a Response to Job Loss," Journal of Labor Economics 17 (Part 2, October 1999a): S142-69.

. "Mobility and Stability: The Dynamics of Job Change in Labor Markets." in The Handbook of Labor Economics, Vol. 3B. Edited by Orley Ashenfelter and David Card, pp. 2439-2483. Amsterdam: North-Holland, 1999b.

Farber, Henry S. and Helen Levy, "Recent Trends in Employer-Sponsored Health Insurance Coverage: Are Bad Jobs Getting Worse?” Journal of Health Economics 19 (January 2000): 93-119.

Freeman, Richard B. "Longitudinal Analyses of the Effects of Trade Unions." Journal of Labor Economics 2 (January 1984): 1-26.

Hersch, Joni. "Compensating Differentials for Gender-Specific Job Injury Risks.” American Economic Review 88 (June 1998): 598-607.

Hirsch, Barry T., and Edward J. Schumacher. "Monopsony Power and Relative Wages in the Labor Market for Nurses." Journal of Health Economics 14 (October 1995): 443-76.

. "Unions, Wages, and Skills.” Journal of Human Resources 33 (Winter 1998): 201-19.

. "Match Bias in Wage Gap Estimates Due to Earnings Imputation," Journal of Labor Economics, Vol. 22 (July 2004): forthcoming.

Hotchkiss, Julie L. "The Definition of Part-Time Employment: A Switching Regression Model With Unknown Sample Selection.” International Economic Review 32 (November 1991): 899-917. 
Lemieux, Thomas. "The 'Mincer Equation' Thirty Years after Schooling Experience, and Earnings." University of California, Berkeley, Center for Labor Economics Working Paper No. 62, October 2003.

Lettau, Michael K. "Compensation in Part-Time Versus Full-Time Jobs: What if the Job is the Same?" Economic Letters 56 (September 1997): 101-06.

Lundberg, Shelly. "Tied Wage-Hours Offers and the Endogeneity of Wages." Review of Economics and Statistics 67 (August 1985): 405-10.

Manning, Alan and Helen Robinson. "Something in the Way She Moves: A Fresh Look at an Old Gap." Oxford Economic Papers 56 (April 2004): 169-88.

Mocan, H. Naci, and Erdal Tekin. "Nonprofit Sector and Part-Time Work: An Analysis of EmployerEmployee Matched Data of Child Care Workers." Review of Economics and Statistics 85 (February 2003): 38-50.

Montgomery, Mark, and James Cosgrove. "The Effect of Employee Benefits on the Demand for Part-Time Workers." Industrial and Labor Relations Review 47 (October 1993): 87-98.

“Are Part-Time Women Paid Less? A Model with Firm-Specific Effects.” Economic Inquiry 33 (January 1995): 119-33.

Murphy, Kevin M. and Finis Welch. "Empirical Age-Earnings Profiles.” Journal of Labor Economics 8 (April 1990): 202-29.

Nardone, Thomas. "Part-Time Employment: Reasons, Demographics, and Trends." Journal of Labor Research 16 (Summer 1995): 275-92.

Neal, Derek. "The Complexity of Job Mobility Among Young Men.” Journal of Labor Economics, 17 (April 1999): 237-61.

Olson, Craig A. "Do Workers Accept Lower Wages in Exchange for Health Benefits?" Journal of Labor Economics 20 (April 2002, Part 2): S91-S114.

Peracchi, Franco, and Finis Welch. "How Representative Are Matched Cross Sections? Evidence from the Current Population Survey.” Journal of Econometrics 68 (July 1995), 153-79.

Polivka, Anne E., and Jennifer M. Rothgeb. "Overhauling the Current Population Survey: Redesigning the Questionnaire.” Monthly Labor Review 116 (September 1993): 10-28.

Snider, Sarah. "Characteristics of the Part-Time Work Force and Part-Time Employee Participation in Health and Pension Benefits." Journal of Labor Research 16 (Summer 1995): 239-48.

Stratton, Leslie S. "Reexamining Involuntary Part-Time Employment" Journal of Economic and Social Measurement 20 (1994): 95-115.

“Are 'Involuntary' Part-Time Workers Indeed Involuntary?" Industrial and Labor Relations Review 49 (April 1996): 522-36.

U.S. Bureau of Labor Statistics. "National Compensation Survey: Employee Benefits in Private Industry in the United States, March 2003." Summary 04-02, April 2004 (www.bls.gov/ncs/ebs/sp/ebsm0001.pdf). 
Figure 1a: Mean Wage by Hours Worked Among Women, 1995-2002 (in constant 2002 dollars)

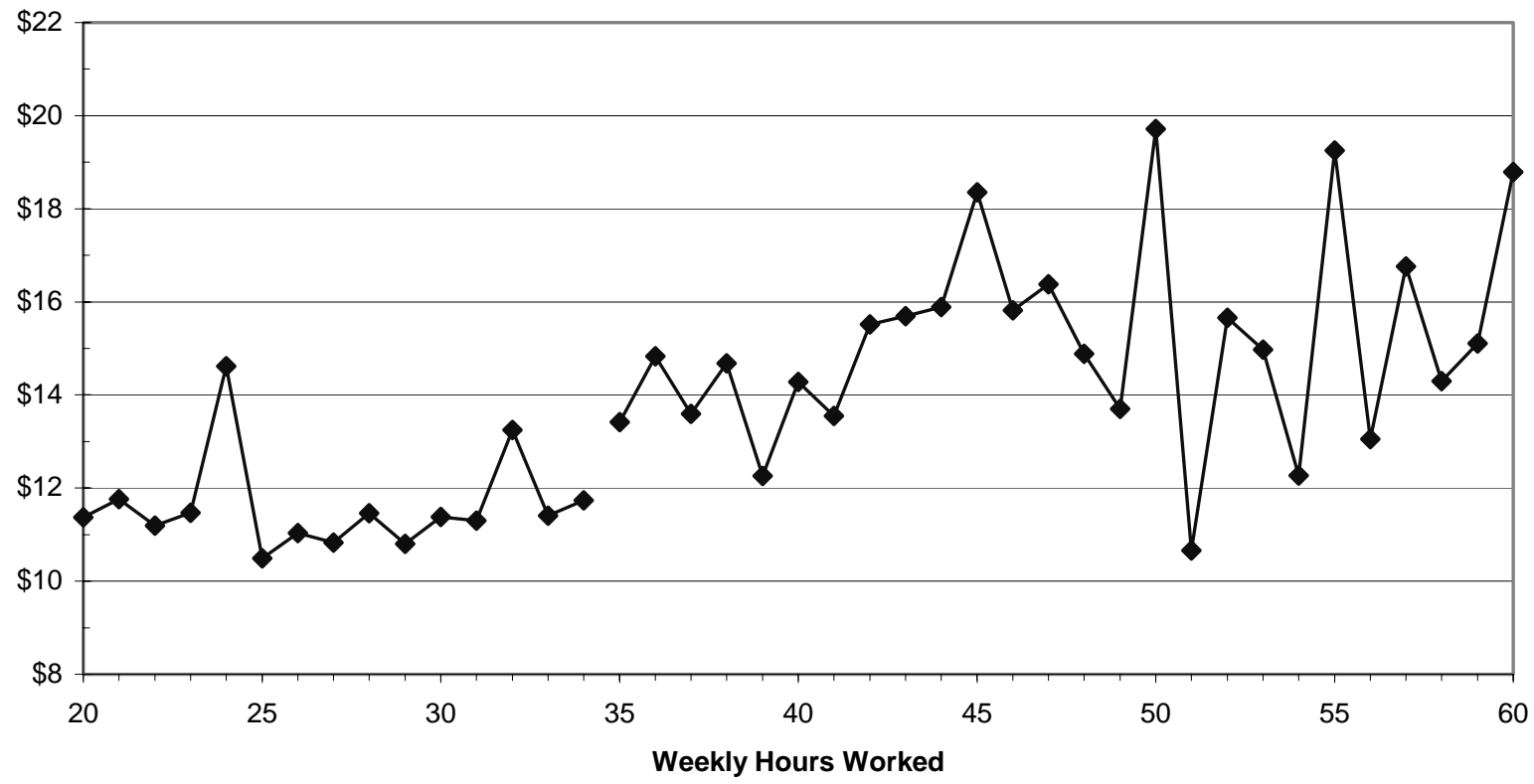

Figure 1b: Mean Wage by Hours Worked Among Men, 1995-2002 (in constant 2002 dollars)

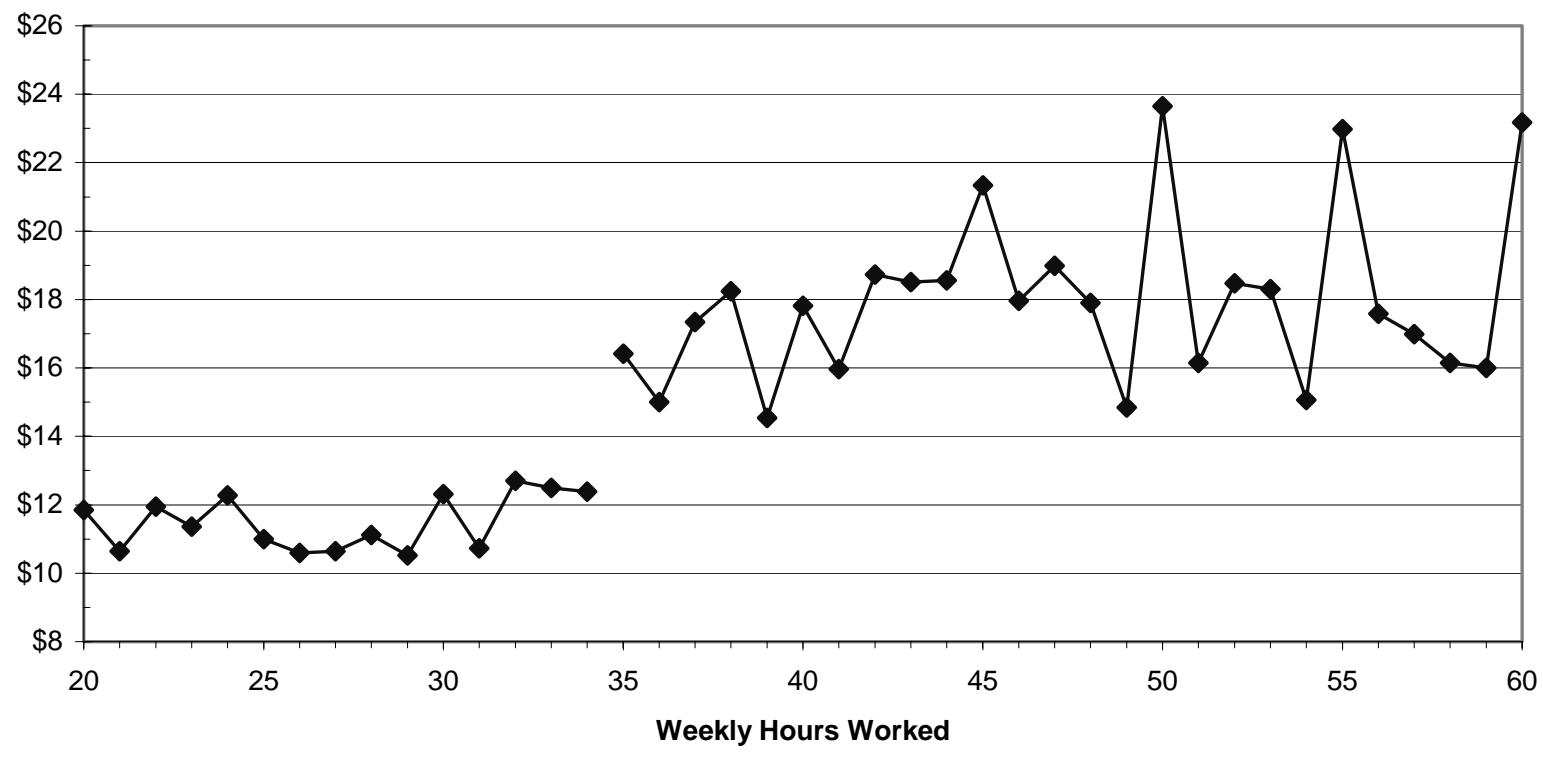


Figure 2: Part-Time/Full-Time Log Wage Gap, by Potential Experience

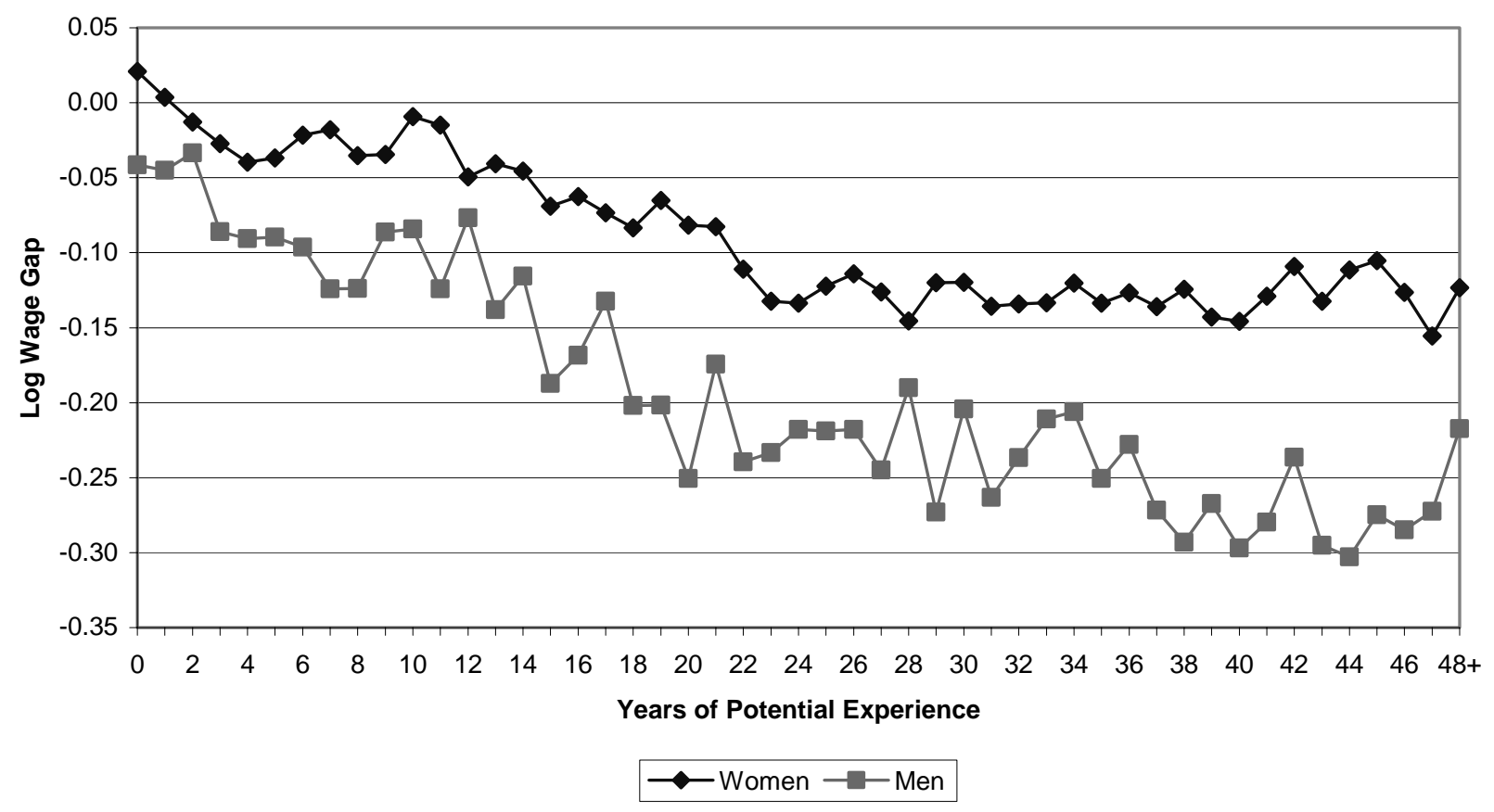


Table 1: Selected Variable Means for Part-Time and Full-Time Female and Male Workers

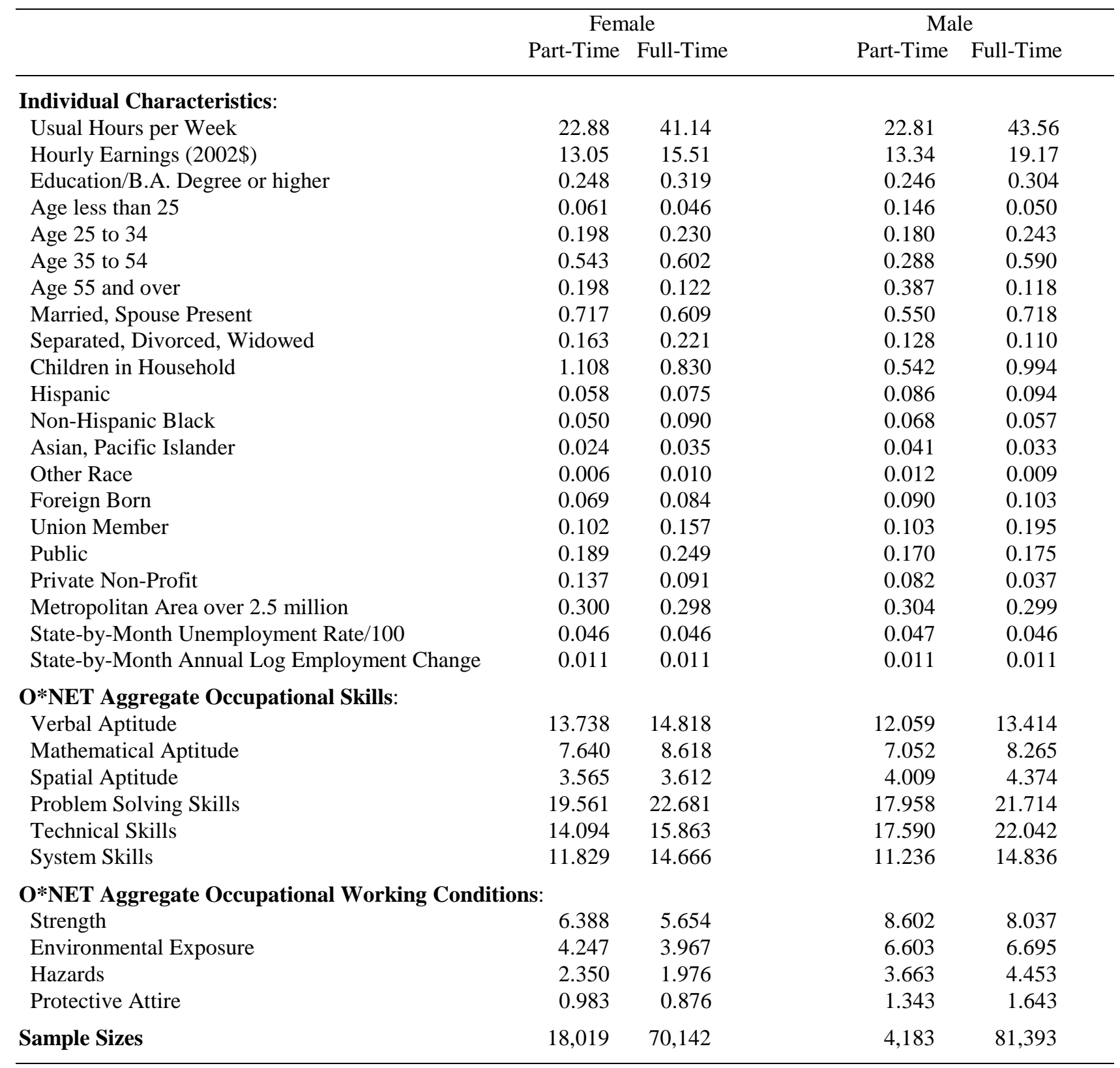

The matched panel sample includes non-student wage and salary workers ages 16 and over (in initial year) employed during consecutive years, from matched panels of the CPS Outgoing Rotation Group (ORG) earnings files for September 1995/96 through 2001/02. Deleted are workers not matched across years and those who in either year have imputed earnings, top-coded earnings, imputed hours worked per week, or extreme wages or wage changes (see text). Means are based on the second year observation for each worker, years 1996-2002. Each of the O*NET occupational variables, matched to individuals in the CPS, are the aggregate of several more detailed $\mathrm{O} * \mathrm{NET}$ variables, as shown in Appendix Table A-1. The detailed rather than aggregate O*NET variables are included in the regressions. Part-time status is determined by whether or not reported usual hours worked per week on the principal job are less than 35 . 
Table 2: Wage Level Estimates of the Part-Time/Full-Time Log Wage Differential

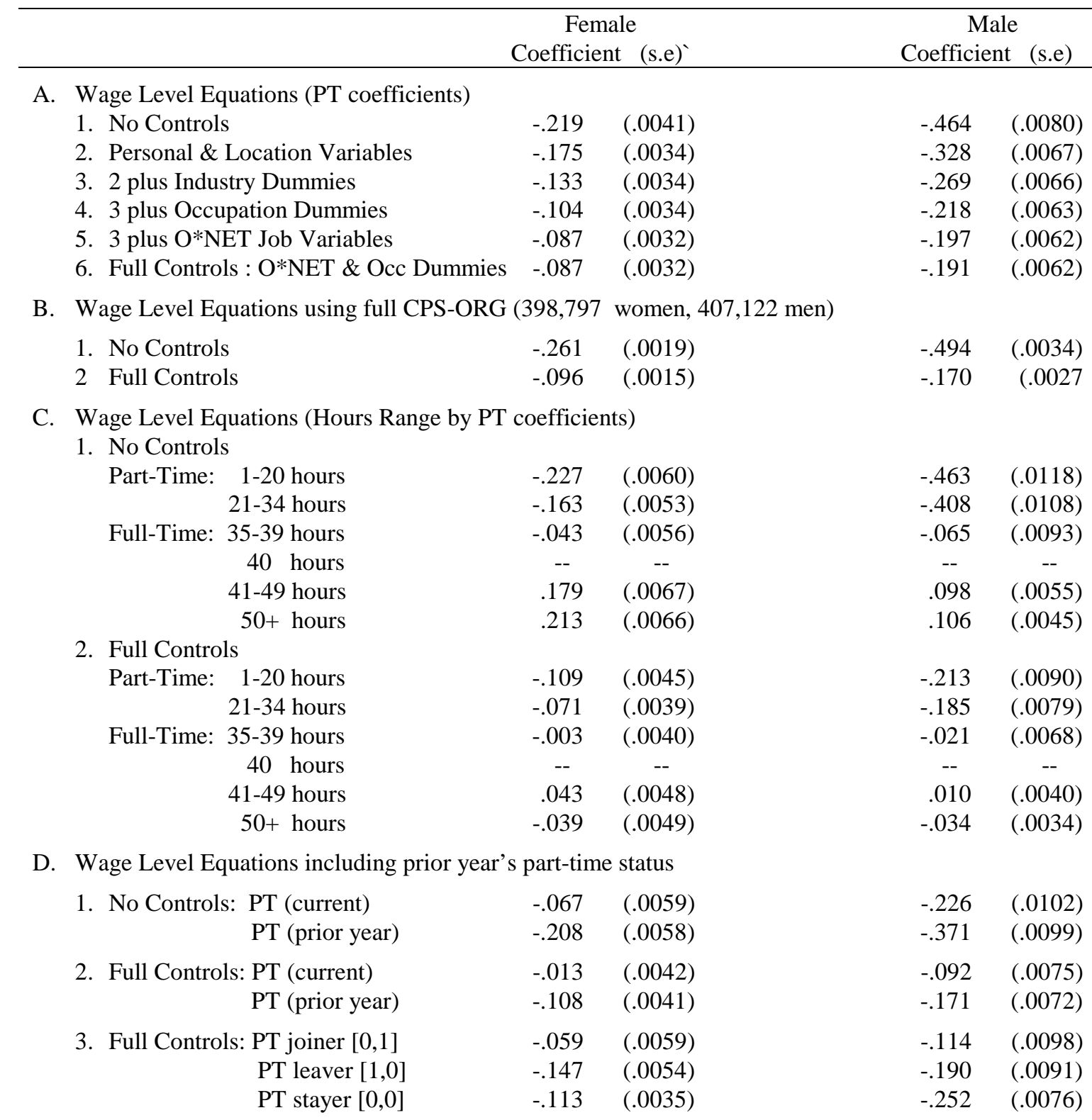

E Wage Level Equations including prior year's PT status. Imputed Earners only (51,670 women; 54,713 men)
1. Full Controls: PT (current)
$-.083 \quad(.0066)$
$-.208 \quad(.0114)$
PT (prior year)
$-.043 \quad(.0064)$
$-.053 \quad(.0111)$
2. Full Controls: PT joiner $[0,1]$
$-.118 \quad(.0061)$
$-.251 \quad(.0123)$
PT leaver $[1,0]$
$-.067 \quad(.0083)$
$-.069 \quad(.0139)$
PT stayer $[0,0]$
$-.110 \quad(.0088)$
$-.226$
(.0145)

\begin{abstract}
Unless otherwise noted, panel sample sizes are 88,161 women and 88,576 men. These samples include nonstudent wage and salary workers ages 17 and over (in year 2) employed during consecutive years, from matched panels of the CPS Outgoing Rotation Group (ORG) earnings files for September 1995/96 through 2001/02. Excluded are workers with imputed earnings, imputed hours, or top-coded earnings in either year. Estimates above are based on second year observations for the years 1996-2002. Variables included in the "Full Controls" regressions are education attainment dummies (7 dummies included), potential experience (minimum of age-schooling-6 or age-16) in quartic form, marital status (2), children (3), race and ethnicity identifiers (4), foreign born, union membership, public, private non-profit, region (8), metropolitan size (6), industry (12), occupation (11), year (6), state-by-month unemployment rate and annual log employment change, and all O*NET variables shown in Appendix Table A1. The sample in Line B includes all CPS outgoing rotation groups (rather than a matched panel) for September 1995 through December 2002. Workers with top-coded earnings are retained and assigned the estimated Pareto mean at the earnings cap. The Imputed Earners matched panel sample in Line E includes workers who satisfy all other CPS panel criteria, but have earnings imputed in years 1,2 , or both.
\end{abstract}


Table 3: Wage Change Estimates of the Part-Time/Full-Time Log Wage Differential

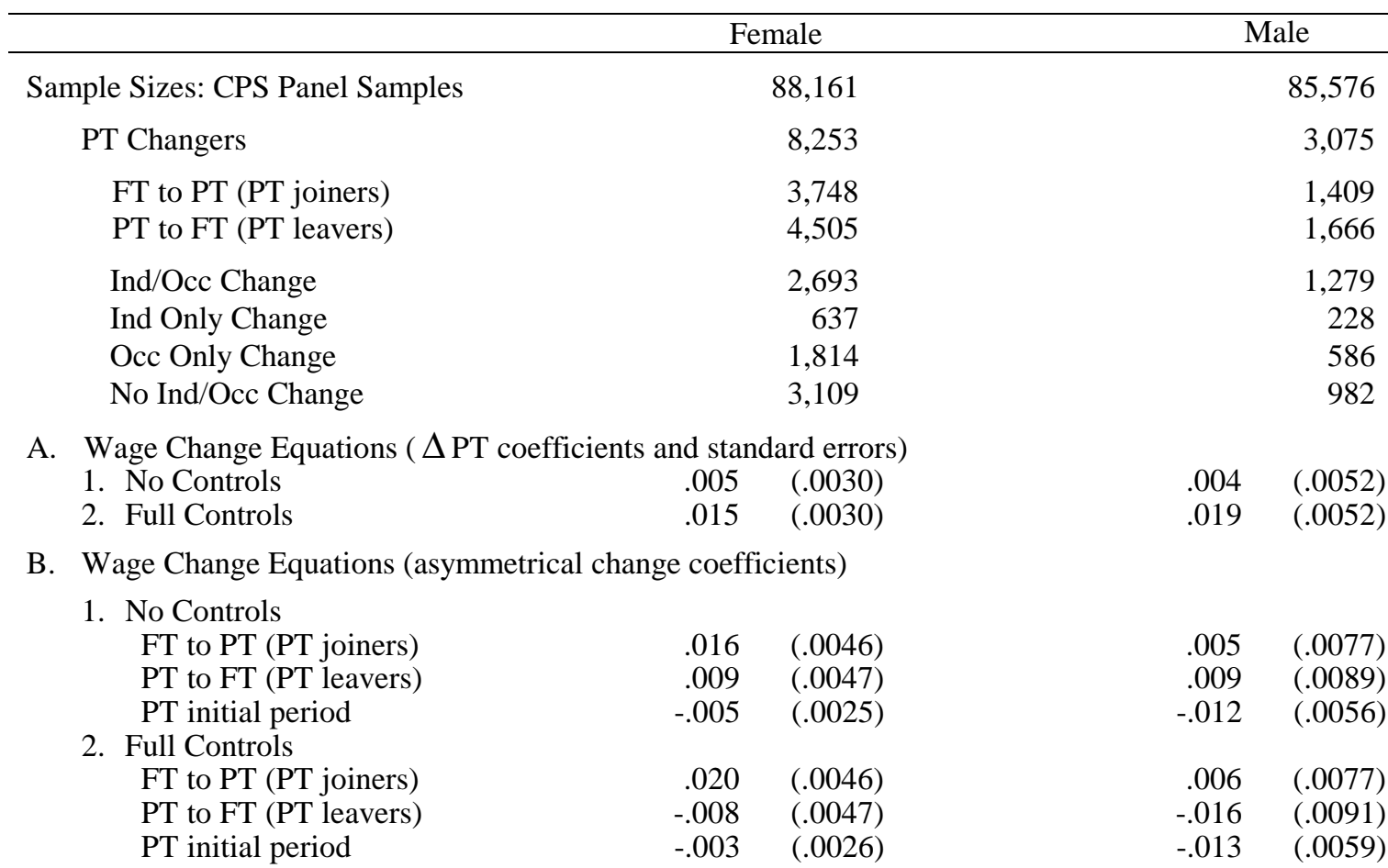

C. Wage Change Equations (Imputed workers only; 51,670 women, 54, 713 men)

1. No Controls

FT to PT (PT joiners)

$\begin{array}{rr}-.079 & (.0120) \\ .071 & (.0132)\end{array}$

$-.196 \quad(.0199)$

PT to FT (PT leavers)

$.002 \quad(.0078)$

$.168 \quad(.0245)$

PT initial period

$.017 \quad(.0159)$

2. Full Controls

FT to PT (PT joiners)

PT to FT (PT leavers)

$-.070 \quad(.0119)$

$-.184 \quad(.0198)$

PT initial period

$.048 \quad(.0132)$

$.128 \quad(.0246)$

$.017 \quad(.0165)$

D. Wage Change Equations ( $\Delta \mathrm{PT}$ coefficients for each Ind/Occ Change group)

1. No Controls (includes separate change dummies)

$\begin{array}{lllll}\text { Ind/Occ Change* } \Delta \mathrm{PT} & -.072 & (.0053) & -.081 & (.0081) \\ \text { Ind Only Change* } \Delta \mathrm{PT} & .007 & (.0108) & .061 & (.0191) \\ \text { Occ Only Change* } \Delta \mathrm{PT} & .023 & (.0064) & .055 & (.0119) \\ \text { No Ind/Occ Change* } \Delta \mathrm{PT} & .062 & (.0049) & .072 & (.0092) \\ \text { Full Controls } & & & & \\ \text { Ind/Occ Change* } \Delta \mathrm{PT} & -.050 & (.0053) & -.057 & (.0081) \\ \text { Ind Only Change* } \Delta \mathrm{PT} & .008 & (.0108) & .065 & (.0189) \\ \text { Occ Only Change* } \Delta \mathrm{PT} & .028 & (.0064) & .067 & (.0118) \\ \text { No Ind/Occ Change* } \Delta \mathrm{PT} & .063 & (.0049) & .076 & (.0091)\end{array}$

E. Wage Change Equations (asymmetrical change coefficients Ind/Occ Changers only)

1. No Controls (Ind/Occ changers only)

$\begin{array}{lrlrl}\text { FT to PT (PT joiners) } & -.090 & (.0086) & -.095 & (.0122) \\ \text { PT to FT (PT leavers) } & .055 & (.0091) & .068 & (.0163) \\ \text { PT initial period } & .004 & (.0065) & .001 & (.0124) \\ \text { Full Controls (Ind/Occ changers only) } & & & & \\ \text { FT to PT (PT joiners) } & -.074 & (.0086) & -.087 & (.0122) \\ \text { PT to FT (PT leavers) } & .029 & (.0091) & .038 & (.0163) \\ \text { PT initial period } & .003 & (.0064) & -.006 & (.0124)\end{array}$

See Table 2 note and text. Change variables in "Full Controls" models are the higher-order experience terms, union membership (interacted with Ind/Occ change), public sector, private non-profit, broad industry (12), broad occupation (11), and all O*NET variables in Appendix Table A-1. Also included are state-by-month unemployment and annual log employment change and dummies for type of detailed Ind/Occ change (3) and year (6). 
Table 4: Tenure Differences Between Part-Time and Full-Time Workers

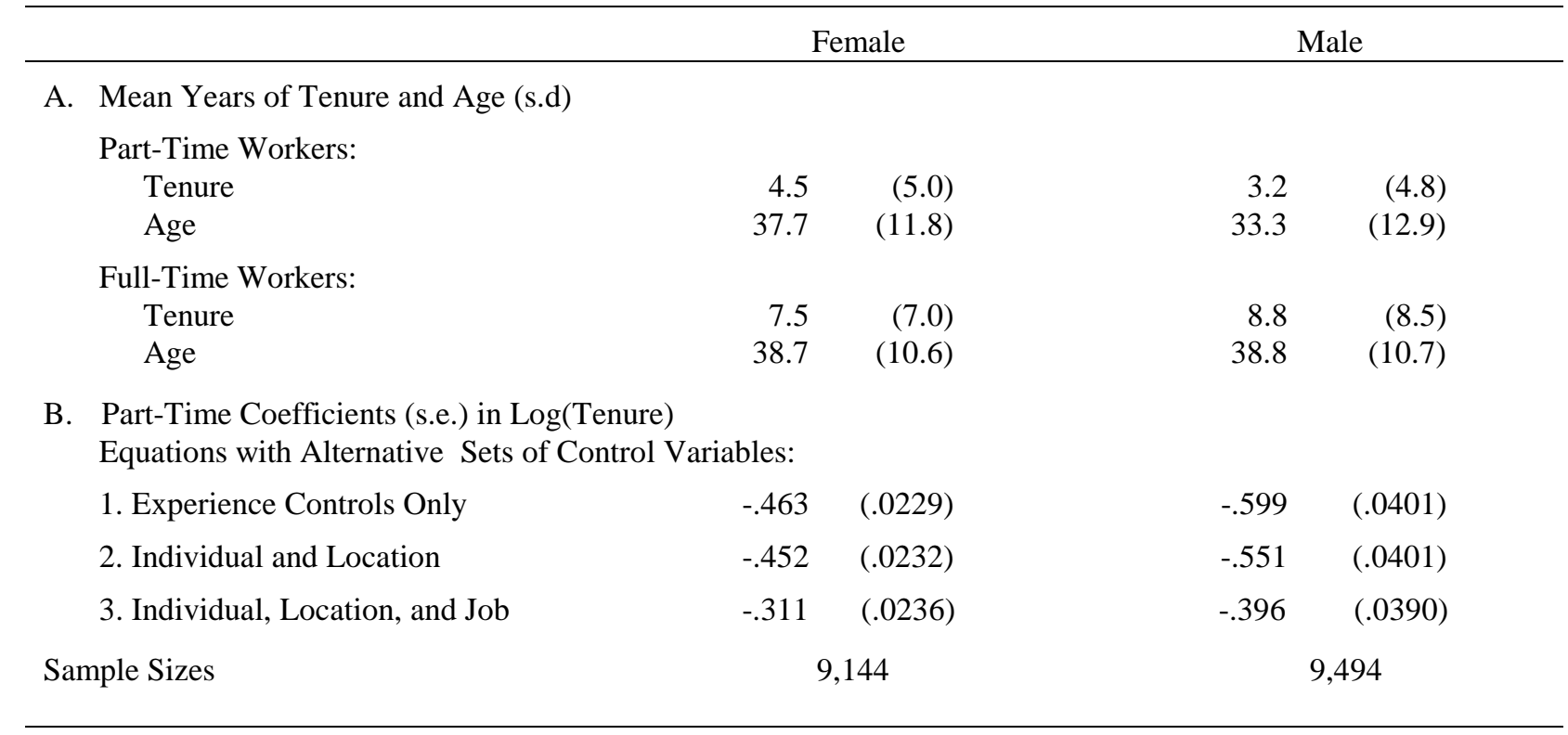

Data source for Line A is the April 1993 CPS Benefit Supplement. Sample includes wage and salary workers ages 20-64. Line B $\log$ (Tenure) regressions: (1) includes part-time dummy, potential experience, and experience squared; (2) adds years of schooling, number of children, and dummies for race, marital status, region, and large metropolitan area; (3) adds firm size dummies, union status, and industry and occupation dummies. 


\section{Appendix Table A-1: O*NET Variable Means for Part-Time and}

Full-Time Female and Male Workers

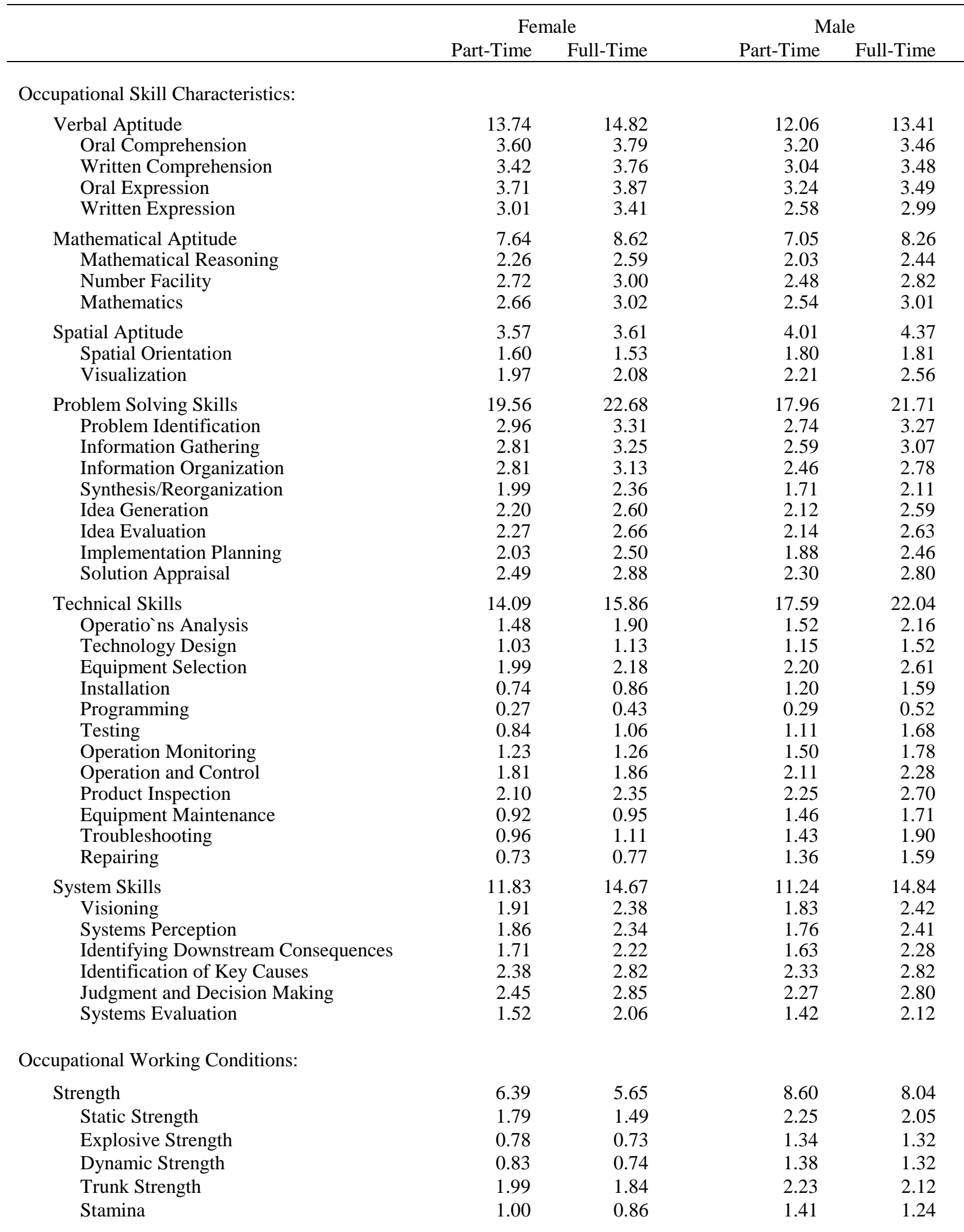

(Appendix A-1 continued on next page) 
Appendix Table A-1 (continued): O*NET Variable Means

\begin{tabular}{lrrrr}
\hline & \multicolumn{2}{c}{ Female } & \multicolumn{2}{c}{ Male } \\
& Part-Time & Full-Time & Part-Time & Full-Time \\
\hline & & & & \\
Environmental Exposure & 4.25 & 3.97 & 6.60 & 6.70 \\
Sounds, Noise Levels are Distracting & 0.81 & 0.77 & 1.14 & 1.19 \\
Very Hot or Cold & 0.64 & 0.60 & 1.05 & 1.02 \\
Extremely Bright or Inadequate Light & 0.65 & 0.59 & 0.93 & 0.91 \\
Contaminants & 0.78 & 0.72 & 1.13 & 1.17 \\
Cramped Work Space, Awkward Position & 0.34 & 0.32 & 0.61 & 0.69 \\
Whole Body Vibration & 0.05 & 0.07 & 0.25 & 0.32 \\
Outdoors & 0.98 & 0.89 & 1.51 & 1.39 \\
Hazards & 2.35 & 1.98 & 3.66 & 4.45 \\
Radiation & 0.07 & 0.04 & 0.03 & 0.04 \\
Disease & 1.18 & 0.76 & 0.25 & 0.18 \\
High Places & 0.05 & 0.07 & 0.36 & 0.55 \\
Hazardous Conditions & 0.21 & 0.25 & 0.80 & 1.16 \\
Hazardous Equipment & 0.38 & 0.50 & 1.52 & 1.99 \\
Hazardous Situations & 0.70 & 0.55 & 1.21 & 1.19 \\
Protective Attire & 0.98 & 0.88 & 1.34 & 1.64 \\
Common Protective or Safety Attire & 0.84 & 0.73 & 1.12 & 1.32 \\
Specialized Protective/Safety Attire & 0.15 & 0.15 & 0.22 & 0.33 \\
Sample Sizes & 18,109 & 70,142 & 4,183 & 81,393 \\
\hline
\end{tabular}

Means of the O*NET occupational variables are calculated across individuals in the CPS (see the text and note to Table 1). The top variable listed in each category is an aggregate variable representing the sum of $\mathrm{O}$ *NET variables listed below. Scaling varies among the detailed O*NET variables, but most are scaled 0-7. Detailed O*NET variables are included in the regressions. The Occupational Information Network ( $\mathrm{O} * \mathrm{NET})$ is a comprehensive database system for collecting, organizing, and describing data on job characteristics and worker attributes. O*NET is sponsored by the U.S. Department of Labor's Employment and Training Administration and is intended to replace the Dictionary of Occupational Titles (DOT). Data are from O*NET 98, Version 1.0, containing 484 variables for 1,122 occupations. The O*NET database was created by job analysts, based primarily on detailed job analyses, many conducted as part of the DOT. Occupational information is being gathered on an on-going basis in order to regularly update $\mathrm{O} *$ NET. O*NET 98 provides a cross-walk mapping 1,122 $\mathrm{O} *$ NET codes to the approximately 500 Census occupational codes in the CPS. The cross-walk is generally clear-cut, with many O*NET and Census occupations mapping one-to-one. Where more than one $\mathrm{O}^{*} \mathrm{NET}$ occupation is assigned to a Census occupation, mean values of the $\mathrm{O} *$ NET variables are calculated. In a small number of cases where no $\mathrm{O} * \mathrm{NET}$ occupation maps directly to the Census, close occupational matches were readily identified. 